\title{
Porous titania photoelectrodes built on a Ti-web of microfibers for polymeric electrolyte membrane photoelectrochemical (PEM-PEC) cell applications
}

\author{
G. Zafeiropoulos ${ }^{a}$, T. Stoll ${ }^{a}$, I. Dogan ${ }^{a}$, M. Mamlouk ${ }^{b}$, M.C.M. van de Sanden ${ }^{a}$, M.N. Tsampas ${ }^{a, *}$ \\ ${ }^{a}$ Dutch Institute For Fundamental Energy Research (DIFFER), De Zaale 20, Eindhoven, 5612AJ, Netherlands \\ bUniversity of Newcastle, School of Chemical Engineering and Advanced Materials, Merz CourtNewcastle upon \\ Tyne NE1 7RU, UK \\ *Corresponding author: $\underline{\text { m.tsampas@differ.nl }}$
}

\begin{abstract}
Conventional photoelectrochemical (PEC) cells are based on planar photoelectrodes supported on glass substrates and liquid electrolytes. Only few recent studies have examined an alternative PEC design which is robust and scalable, where the key elements are polymeric electrolyte membranes and porous photoelectrodes. This work aims to give further insights on the operation of such cells utilizing titania photoelectrodes and proton and hydroxide ion conducting membranes. Two families of photoelectrodes were developed on $\mathrm{Ti}$ porous substrate; $\mathrm{TiO}_{2}$ nanotubes grown by anodization and subsequent oxygen annealing, and $\mathrm{TiO}_{2}$ layers developed under oxygen annealing. Initial screening of the photoanodes for water splitting and (poly)alcohol photo-oxidation took place in conventional PEC cells. We found that the annealing temperature affects the performance of the photoanodes, evidenced by a monotonic increase in the activity for water photo-oxidation with increasing annealing temperature. Moreover it was demonstrated that anatase phase is predominantly active for the (poly)alcohol electro-oxidation, while there is a synergy between rutile and anatase which is beneficial for water splitting. In addition, the most promising photoanodes for water splitting were evaluated in our polymeric electrolyte membrane photoelectrochemical (PEM-PEC) cell during gas phase operation. It was found that PEM-PEC operation is more efficient when $\mathrm{OH}^{-}$conducting membranes are used, while the nature of the carrier gas does not significantly influence the activity. Overall, PEM-PEC operation is more promising than conventional PEC in both acidic and alkaline media, since comparable (or even at some cases higher) photocurrents were obtained while liquid pumping systems are not required for PEM-PEC devices.
\end{abstract}

Keywords: $\mathrm{Ti}$ web of microfibers; $\mathrm{TiO}_{2}$ nanotubes and layers photoanodes; Photoelectrochemical $\mathrm{H}_{2}$ production; Gas phase operation; $\mathrm{H}^{+}$or $\mathrm{OH}^{-}$conductive polymeric electrolytes

\section{Introduction}

One of the most important technical problems facing humanity is the development of a long-term, sustainable energy economy [1]. Global energy consumption is projected to increase at least 2-fold by midcentury relative to the present because of population and economic growth. This demand could be met, in principle, from fossil energy resources, particularly coal [2]. Taking into account the current consumption rate, estimated reserves range from 150 to 400 years for coal, 40 to 80 years for oil and 60 to 160 years for natural gas [3]. However this strategy could come with catastrophic societal costs due to the cumulative nature of $\mathrm{CO}_{2}$ emissions in the atmosphere from burning carbon-based fossil fuels [4].Scientific discovery and innovation will be vital to achieve environmentally sound and costeffective solutions $[1-3,5]$.It is clear that a significant increase in production of renewable energy is 
necessary to alleviate the environmental issues associated with the use (combustion) of fossil fuels [19]. Concurrently, storage of renewable energy is required, since most of these sources, and in particular solar energy, are intermittent, both in the short term (day vs. night) and in the long term (summer vs. winter).

Solar photoelectrochemical (PEC) hydrogen production is one of the promising technologies that could potentially provide a clean, cost-effective and domestically produced energy carrier. It is also sustainable since the energy received hourly on Earth's surface is sufficient to fully provide mankind's annual energy demand [1-3,5-9]. The concept of PEC water splitting is realized in an electrochemical cell where a photoactive working electrode is used to promote an electrocatalytic reaction. In the case of a semiconductor-based working electrode for water splitting, the fundamental principles can be briefly described as follows: upon illumination, an electron is excited to the conduction band, leaving a hole in the valence band. Then these separated charge carriers react with water to form hydrogen (via the electrons) or oxygen (via the holes). Thus, intermittent solar energy is converted into an inherently more storable form of energy, i.e. in the form of chemical bonds. Note that in a non-ideal case, an electrochemical bias has to be applied to ensure a sufficient charge carrier mobility and to minimize the electron-hole pair recombination [1-3,5-9].

Since the pioneering work by Fujishima and Honda in 1972 [10] on photolysis of water, most of the photoelectrochemical (PEC) cells described in literature so far utilize a similar design based on aqueous phase electrolytes [1-3,5-9]. Inspired by the reactor design of polymeric electrolyte membrane (PEM) electrolyzers/fuel cells [11], few groups have attempted to separate the two electrochemical halfreactions with a polymeric electrolyte membrane [12-26]. The PEM-PEC cell design is advantageous compared to PEC cells with liquid electrolyte since it is more robust and potentially more scalable, the polymeric membrane does not need replenishment during prolonged operation and also direct separation of the reaction products is possible during gas-phase photoelectrochemical experiments. In our group, we recently developed a novel PEM-PEC cell design [26], which is equipped with a reference electrode. Our unique design allowed for the first time a direct comparison of the performance of PEM-PEC with conventional (aqueous) PEC cells [26].

In the conventional PEC approach, the photoelectrode is built on a glass substrate, whereas PEM-PEC photoelectrodes require a more complex design. High porosity is required in order to facilitate the supply of gaseous reactants to the electrode/electrolyte interfaces. In our previous study [26], we have introduced a new class of photoanodes based on a 3D electrode backbone made of microstructured titanium web. Titania nanotube arrays were developed by electrochemical anodization, which is one of the most efficient and simple ways to generate $\mathrm{TiO}_{2}$ nanostructures [26-29]. Most studies on titania nanotube arrays (TNTAs) are focused on the growth of nanotube layers on planar surfaces (such as flat titanium foils) and less on the curved and complex surfaces (such as wires, meshes, and hollow tubes) which are more interesting for many applications [30]. Anodization of a Ti-web of microfibers has been very recently reported as a template for loading Pd nanoparticles for alcohol electro-reforming [29] and also reported by our group for gas phase photoelectrochemistry [26].

Our present study addresses one of the main challenges for further development of the PEM-PEC technology that is the photoelectrode design. Based on this, the primary goal of the present work the optimization of our novel photoelectrodes, while the second goal was to introduce the most promising photoanodes in two possible PEM-PEC cell configurations. 
Initially, optimization of our novel photoelectrodes was conducted by identifying the most appropriate conditions during the two steps of the development process: the anodization and the subsequent calcination. The initial screening of the photoanodes activity was carried out in a conventional PEC reactor during water splitting and (poly)alcohol electro-oxidation.

In the course of these investigations, it appeared that rutile:anatase ratio in the photoelectrodes strongly influences the photoelectrochemical activity. In order to investigate this furher, a second class of photoanodes was developed by oxygen annealing of the $\mathrm{Ti}$ web, which results in $\mathrm{TiO}_{2}$ layers at the exterior of the Ti-web. Our results showed that anatase phase is predominantly active for the (poly)alcohol electro-oxidation, while there is a synergy between rutile and anatase which is beneficial for water splitting.

In a second step, the most promising photoanodes were introduced in PEM-PEC cells and our work was focused on optimizing the cell design and operation conditions during steam water splitting. To achieve this, three methodology lines were followed:

(i) The membrane-electrode assemblies were completed by using two different types of polymeric membranes, with either protonic or hydroxide ion conductivity. In a recent publication, Arico et al. [31]used model $\mathrm{TiO}_{2}$-based photoanodes supported on a coated glass and exposed them to deaerated water. They showed that the electrolyte environment can strongly influence the surface of photoanodes during water splitting. To our knowledge, our study is the first to report the use of $\mathrm{OH}^{-}$conducting membranes in PEM-PEC cells in conjunction with high surface area optimized photoanodes and during gas phase operation.

(ii) Gas phase operation was enabled by passing a carrier gas through a thermostated water saturator. He and air were used as the carrier gas in view of practical applications of the system, since the latter case resembles natural convection for capturing the water molecules contained in ambient air $[19,20,26]$. Even though the concept of air-based operation of PEM-PEC electrolyzers is not new, this is the first time that the efficiency during this operation mode is compared using $\mathrm{H}^{+}$and $\mathrm{OH}^{-}$conducting membranes.

(iii) Our PEM-PEC design allows direct comparison of the efficiency of photoanodes during PEM-PEC operation (with 3.5\% water steam) and conventional PEC operation (liquid water) due to the presence of a reliable reference electrode. Such a comparison is carried out for the first time in the present study for both acidic and alkaline conditions.

Overall, it was found that PEM-PEC operation is more efficient when $\mathrm{OH}^{-}$conducting membranes are used, while the nature of the carrier gas does not significantly influence the activity. PEM-PEC operation is more promising than conventional PEC in both acidic and alkaline media, since comparable (or even at some cases higher) photocurrents were obtained. Moreover, liquid pumping systems are not required for PEM-PEC devices.

\section{Experimental}

\subsection{Photoanodes}

Two classes of photoanodes were prepared (Fig.1). The first class (TNTAs) includes $\mathrm{TiO}_{2}$ nanotube arrays developed through anodization of a Ti-web of microfibers and its subsequent calcination. For the second class of photoanodes $\left(\mathrm{TiO}_{2}\right.$ layers), a Ti-web was coated by $\mathrm{TiO}_{2}$ by oxygen annealing 
(without prior anodization). Both classes of photoanodes were characterized and the photoelectrochemical performances of anodized and non-anodized photoanodes was compared.

\subsection{Preparation of $\mathrm{TiO}_{2}$ nanotube arrays}

Prior to anodization, Ti-webs (gas diffusion layer, Bekinit [32,33], $20 \mu \mathrm{m}$ microfibers, 80\% porosity, Fig. 1) were cleaned by sonication in acetone and in ethanol for $20 \mathrm{~min}$, respectively and rinsed with deionized water. All the experiments were performed in the electrolyte containing ethylene glycol (anhydrous 99.8\%, Sigma Aldrich) $0.3 \mathrm{wt} \%$ ammonium fluoride (98+\% ACS reagent, Sigma Aldrich) and 2 vol\% deionized water.

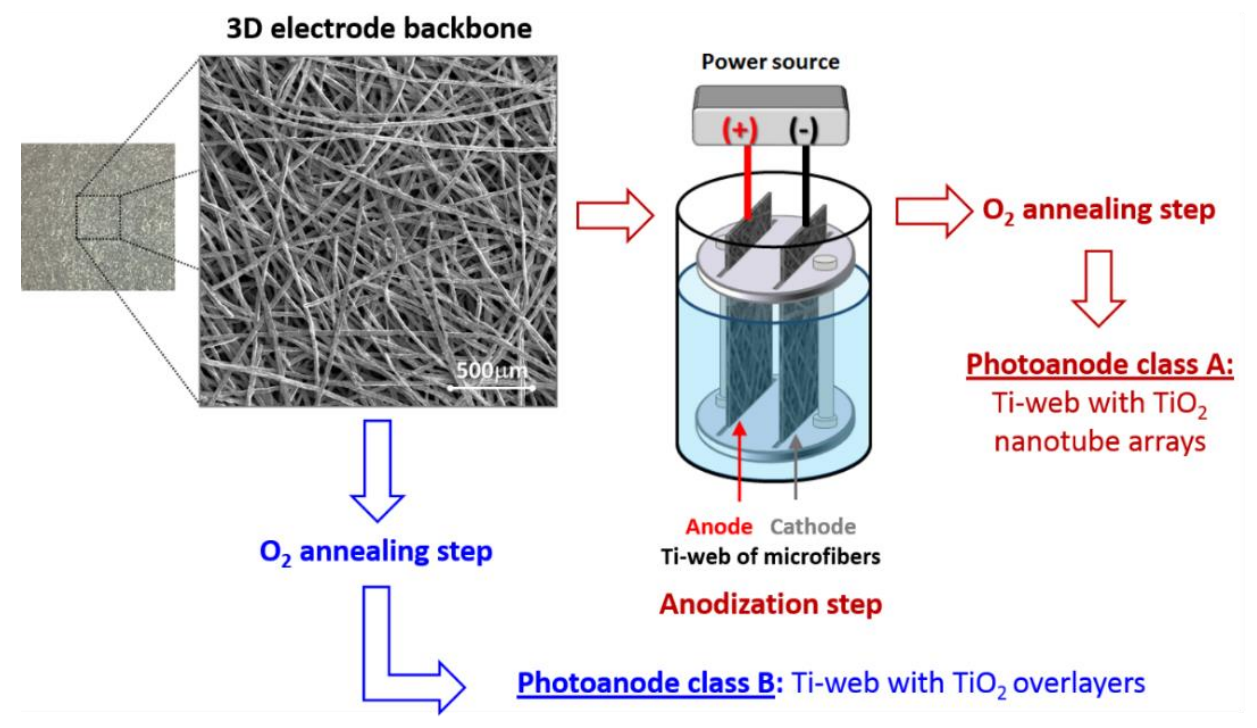

Fig. 1 Scheme of fabrication route for the development of the two photoanodes classes.

In order to achieve well-adherent and mechanically stable titania nanotube arrays (TNTAs) on our substrates with minimum cracks we followed a recently proposed strategy which is based on the aging of the electrolyte $[26,30]$. The term "aging" here, is used to represent the anodization of a flat Ti-foil "dummy sample" for $10 \mathrm{~h}$ prior to anodization of Ti-web. After each run, fresh electrolyte was prepared, which was aged before use for the next Ti-web. A DC power source, ES075-2 Delta Electronica, was used to impose potentials (without ramping) and to record transient currents. All the experiments were conducted at room temperature without stirring. Titania nanotube arrays were generated by potentiostatic anodization under a constant applied potential of $30 \mathrm{~V}$ for various anodization times. After the anodization, the samples were properly rinsed with deionized water to remove the occluded ions and then were calcined for $5 \mathrm{~h}$ under air to increase the crystallinity.

\subsection{Morphology and crystal characterization of TNTAs}

Surface morphologies of the TNTAs were characterized with a scanning electron microscope (FEI Quanta 3D FEG instrument) at an acceleration voltage of $15 \mathrm{keV}$ and working distance of $10 \mathrm{~mm}$. The crystal phases were analyzed by X-ray diffraction (Brucker D8 Advance Eco) using a Cu $\mathrm{K}_{\mathrm{a}}$ tube. Raman spectroscopy measurements were performed with a Renishaw Raman microscope equipped with a $514 \mathrm{~nm}$ laser, a grating with 1800 linesmm $^{-1}$, and a CCD detector, and with a measurement step size of $1.7 \mathrm{~cm}^{-1}$. The laser power during measurements is fixed at $0.3 \mathrm{Wmm} \mathrm{mm}^{-2} \cdot \mathrm{N}_{2}$ adsorption measurements were carried out Tristar 3000 automated gas adsorption system. Brunauer-Emmett-Teller (BET) method was used to determine the surface area. Prior to analysis, the samples were degassed at $100^{\circ} \mathrm{C}$ under vacuum overnight. 


\subsection{Photoelectrochemical characterization}

A conventional three electrode PEC cell $[1,8,9]$, with a Pt wire (Sigma Aldrich) as counter electrode and a $\mathrm{Ag} / \mathrm{AgCl}$ reference electrode ( $\mathrm{ALS}$ Japan) was used for the evaluation of the photoanodes with liquid media at $\mathrm{pH}=1\left(0.1 \mathrm{M} \mathrm{H}_{2} \mathrm{SO}_{4}\right)$ for water splitting (i)alone and (ii) with the addition of either methanol, ethanol, isopropanol or glycerol $(0.1 \mathrm{M})$. The best performing photoanodes were also evaluated for gas phase operation in our custom built PEM-PEC cell [26] (Fig.2). Our PEM-PEC cell is equipped with a reliable hydrogen reference electrode and thus allows for performance comparison with conventional aqueous phase PEC cells. All the linear sweep voltammetry measurements were obtained at a scan speed of $2.5 \mathrm{mVs}^{-1}$ using a chopped illumination from a LED source $\left(365 \mathrm{~nm}, 9 \mathrm{~mW} \cdot \mathrm{cm}^{-2}\right)$. The power level of the LED is higher than the 1 Sun thus for comparison purposes, Fig. S1 depicts the performance of the most promising photoanodes under AM1.5G illumination.

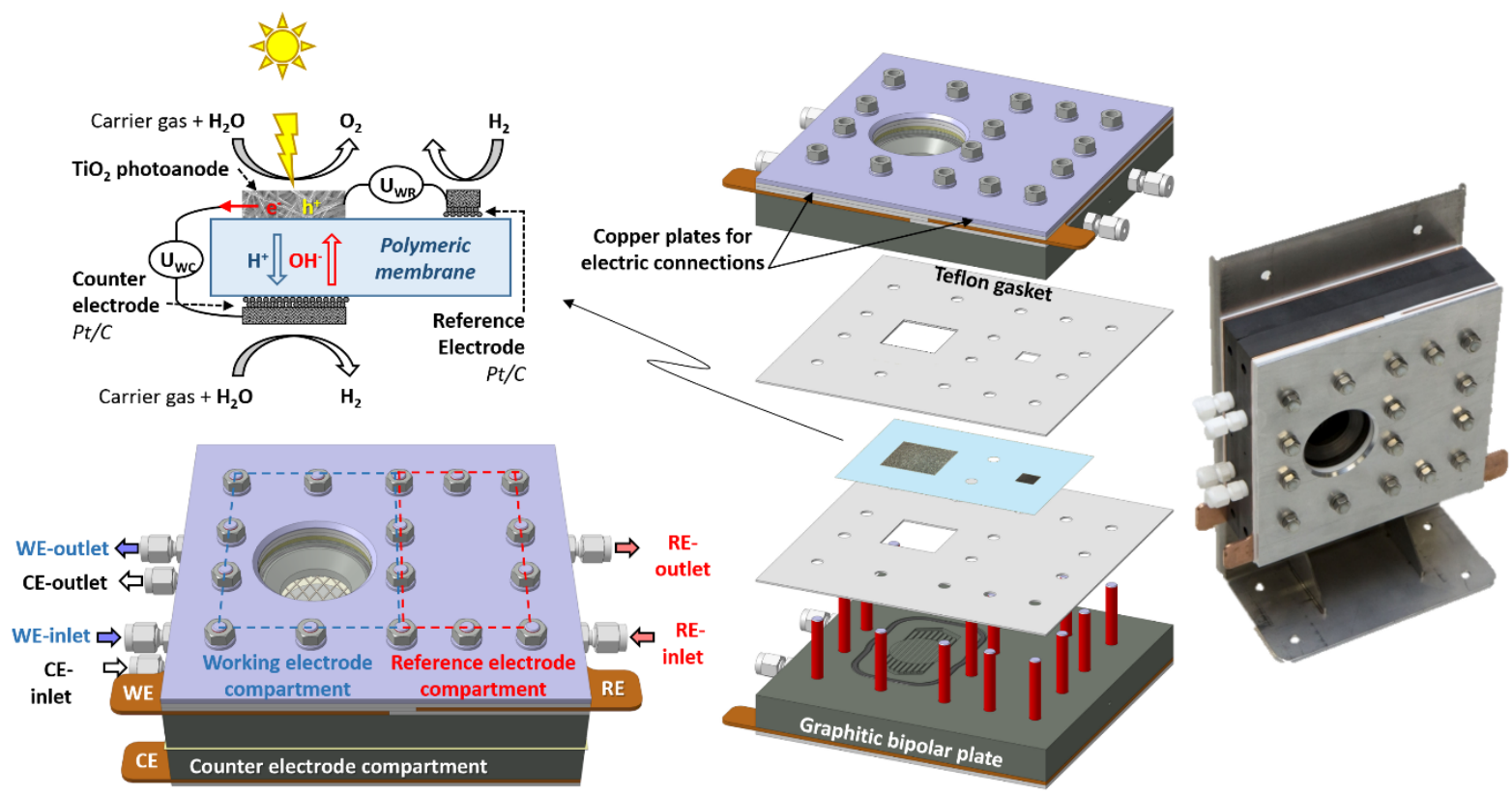

Fig. 2 (Left) Configuration and operation of the membrane (photo) electrode assembly utilizing either proton or hydroxide ion conductors. (Right) Our PEM-PEC reactor design [26] with three compartments for accommodating anode, cathode and reference electrodes.

\subsection{Membrane (photo) electrode assemblies}

The Ti-web photoanodes $\left(1 \mathrm{~cm}^{2}\right.$ masked area) were placed on the top side of the polymeric membrane. Commercially available Nafion $117^{\circledR}$ perfluorinated membrane (180 $\mu$ m thick, Alfa Aesar) was used as cation $\left(\mathrm{H}^{+}\right)$exchange membrane. The anion $\left(\mathrm{OH}^{-}\right)$exchange membrane $(90 \mu \mathrm{m}$ thick) was synthesised as previously reported $[34,35]$ using low-density polyethylene (LDPE) with vinylbenzyl chloride (VBC) as the graft monomer. Mutual gamma radiation grafting was carried out by Synergy Health plc (Wiltshire, UK) with a total radiation dose of $20 \mathrm{kGy}$. In order to produce the anion exchange functionality, the membrane was immersed in trimethylamine (TMA) $45 \mathrm{wt} \%$ solution in water for $24 \mathrm{~h}$. The counter ion was subsequently exchanged from $\mathrm{Cl}^{-}$to $\mathrm{OH}^{-}$by treating the membrane with fresh 1.0 $\mathrm{M} \mathrm{KOH}$ solution, as previously described [34,35]. Degree of grafting based on initial weight (DOG) is $65.6 \%$ and ion exchange capacity (IEC) is 2.3 mmoleg $^{-1}$.

A Pt counter-electrode (supported on carbon cloth, with $0.5 \mathrm{mgcm}^{-2}$ loading, Fuelcellsetc) was placed at the bottom side of the membrane. The reference electrode, which is also a Pt/C electrode (with the 
same characteristics), was deposited on the top of the membrane as represented in Fig. 2 . The membrane electrode assemblies were pressed between two graphitic flow-fields plates.

The three different compartments (sealed with rubber o-rings) of our home-built PEM-PEC cell are illustrated in Fig. 2. Teflon gaskets are used to electrically isolate anodic and reference current collection, which are on the same side of the cell and are represented by the brown plates. Two $\mathrm{CaF}_{2}$ windows are used to allow illumination and to ensure a sealing of the anodic compartment and an $\mathrm{Au}$ mesh for the current collection. Each compartment was fed with humidified gaseous streams, made by bubbling $\mathrm{He}$, air, or $\mathrm{H}_{2}$ through thermostated gas saturators containing $\mathrm{H}_{2} \mathrm{O}$. Two modes of operations were examined where $3.5 \mathrm{vol} \% \mathrm{H}_{2} \mathrm{O}$ was introduced to the cell via $\mathrm{He}$ or air $\left(100 \mathrm{ml} \mathrm{min} \mathrm{m}^{-1}\right)$ in the anodic side. The cathode was always fed with $3.5 \mathrm{vol} \% \mathrm{H}_{2} \mathrm{O}$ in $\mathrm{He}\left(100 \mathrm{ml} \mathrm{min}^{-1}\right)$ and the reference electrode with 3 vol\% $\mathrm{H}_{2} \mathrm{O}$ in $\mathrm{H}_{2}\left(30 \mathrm{ml} \mathrm{min}^{-1}\right)$.

\section{Results and discussion}

\subsection{Titania nanotube arrays}

In order to achieve an improved understanding of the potential benefits offered by the microstructured anodization substrate, we studied here the effect of anodization time and calcination temperature.

\subsubsection{Effect of anodization time}

Anodization experiments were conducted on a 2-electrode anodization reactor (Fig. 1) following the protocol described in the experimental section. During anodization experiments the main output is the current for an applied potential or vice versa. The current profile can be used as an indicator for the nanotube formation process [36]. Therefore we performed SEM measurements for substrates anodized at different times as indicated on the bottom of Fig. 3a (open symbols). The formation of nanotube arrays on the curved surface of the microfibers leads to lateral tension which creates cracks in the TNTAs. Focusing on a crack of the TNTAs (Fig. 3b), we were able to estimate the length of the TNTAs, which is around $700 \mathrm{~nm}$ after one hour of anodization.

From the SEM image in Fig. $3 c$ we determined the length of the nanotubes as a function of anodization time (top Fig. 3a) and also determined the inner diameter of the nanotubes (i.e. 10-15nm). BET measurements were also performed in order to quantify the surface area of the nanotube arrays and the porosity of the anodized substrates. The outcome of these measurements (see Fig. S2) resulted in a surface area of $2.7 \mathrm{~m}^{2} \mathrm{~g}^{-1}$ and a pore size of between 4 and $11 \mathrm{~nm}$, maximized at 7.4 and $9.7 \mathrm{~nm}$. BET measurements concluded a 33-fold increase in the total surface area upon anodization: considering a superficial electrode surface area of $1 \mathrm{~cm}^{2}$, untreated Ti had a surface area of $40 \mathrm{~cm}^{2}$, while the $\mathrm{TiO}_{2}$ samples produced by anodization for $1 \mathrm{~h}$ had a surface area of $1300 \mathrm{~m}^{2}$.

Based on literature on the anodization process [28-30,36] and on the SEM images (fig.3), the current profile is divided in three regions. Initially $(0-2 \mathrm{~min})$ the current decreased by a factor 2 , due to the formation of a bulk $\mathrm{TiO}_{2}$ layer that increased the substrate resistivity. This is confirmed by the absence of any specific pattern on the SEM images. Between 2 and $10 \mathrm{~min}$, the current slightly increased as a result of increased surface area, due to the successive formation of pits, pores and finally tubes uniformly distributed over the bulky $\mathrm{TiO}_{2}$ layer. The pore growth is caused by an inward movement of the oxide layer at their bottom. Under the applied electrical field, $\mathrm{Ti}^{4+}$ ions migrate from the metal to the oxide/electrolyte and then get dissolved in the fluoride containing environment. Since the rate of the oxide etching and the oxide growth tend to reach an equilibrium, the $\mathrm{TiO}_{2}$ thickness remains the 
same while the pores are getting deeper in the metallic layer to form the tubes. The third region (10 to $60 \mathrm{~min}$ ) can be called the elongation step, where the growth of the nanotubes continued but at a slower rate (especially between 30 and $60 \mathrm{~min}$ Fig. 3a). The growth continued until the oxide dissolution rate at the top of the tubes equilibrates with the inward movement at their bottom.

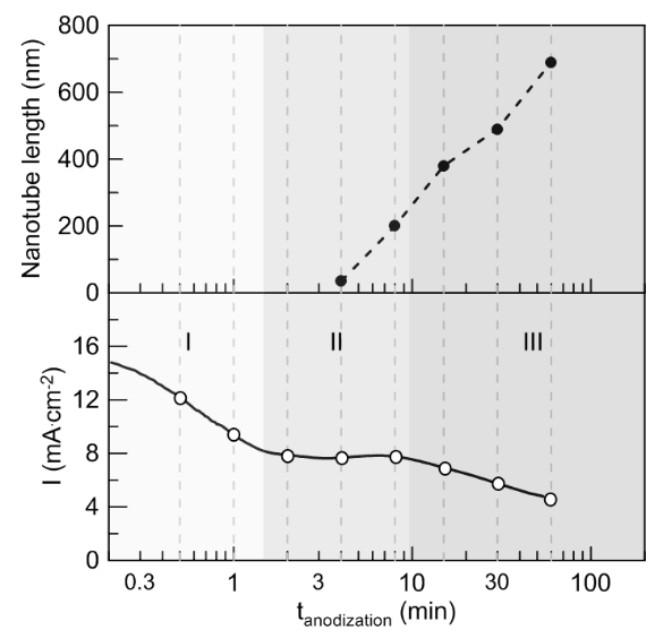

(a)
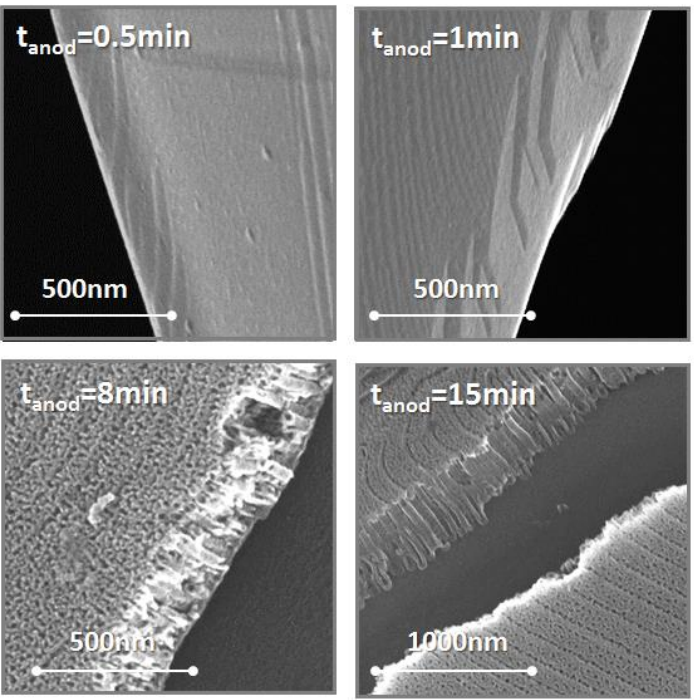

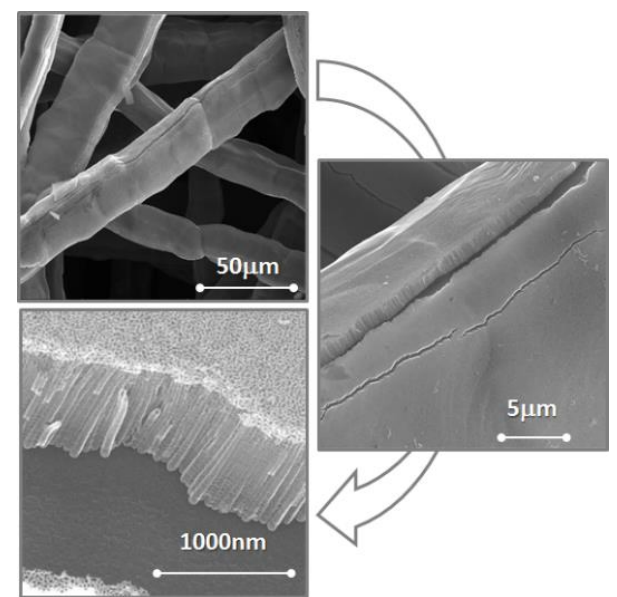

(b)
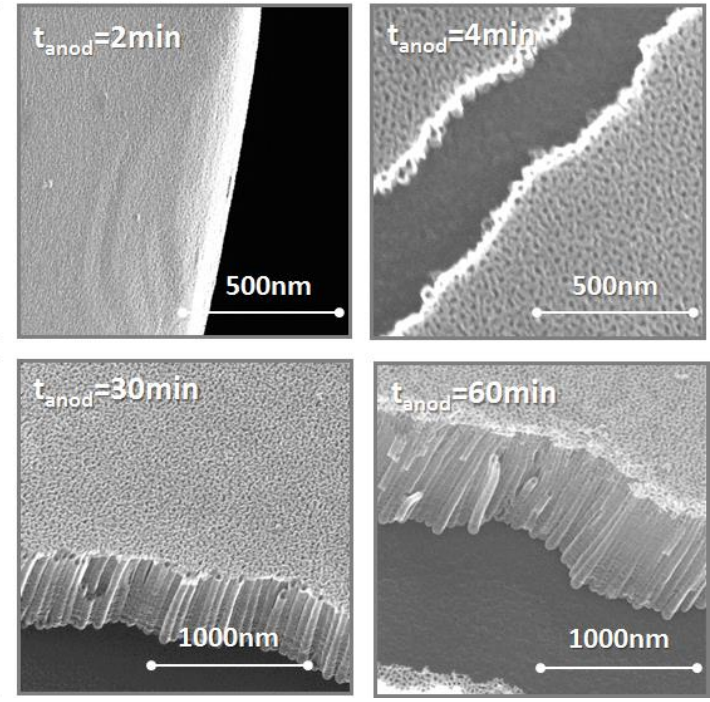

(c)

Fig.3 (a) Anodization current profile upon potentiostatic application of 30V. The length of the TNTAs is also presented as a function of the anodization time. (b)SEM images of $1 \mathrm{~h}$ anodized TNTAs focusing on a single microfiber and on a crack. (c) SEM images of single microfiber at different anodization times.

The calcination step of the anodized substrates is crucial to pass from the poorly active as-generated amorphous $\mathrm{TiO}_{2}$ to a more active crystalline structure. The three main phases of $\mathrm{TiO}_{2}$ are brookite, anatase and rutile, the latter two being the most suitable and commonly used for photoactivated processes $[30,36]$. In literature of $\mathrm{TiO}_{2}$ nanotubes, it is demonstrated that the highest anatase phase is observed with calcination temperature of $450^{\circ} \mathrm{C}[30,36-37]$. Therefore, we have used this temperature as a starting point of our experiments.

The photocurrent from the photoanodes fabricated with different anodization times, realized with linear sweep voltammetry under chopped UV-light illumination, is depicted in Fig. 4. It clearly appears 
that the anodization time and hence the tube length is correlated with the activity: the longer the tube, the higher the obtained photocurrent. Due to the logarithmic dependence of the nanotube length with the anodization time, the effect of anodization time on the photocurrent is more intense at short anodization times (i.e. 2-15 min) while it is less important for the 30-60 min of anodization. Thus for the photoanodes that are presented in the following experiments we used $1 \mathrm{~h}$ as anodization time.

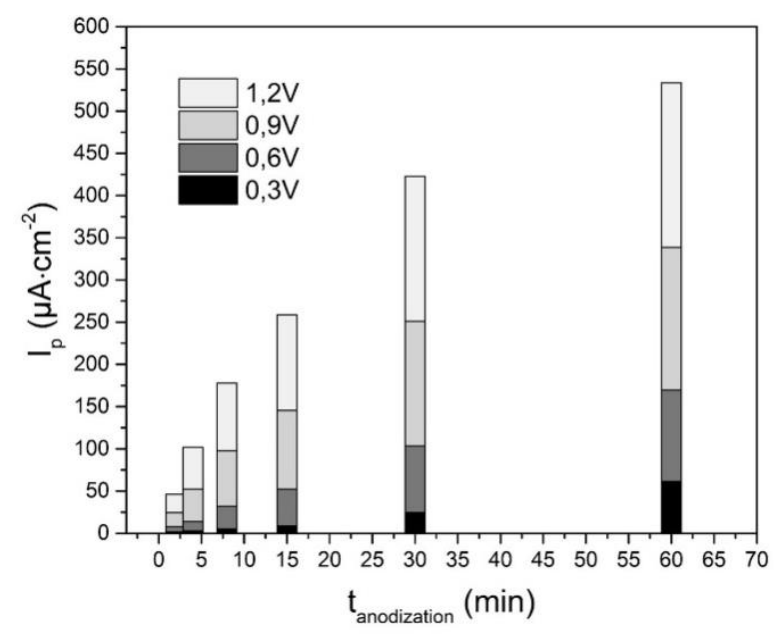

Fig.4 Photocurrent response of titanium substrates at different applied potential (vs RHE), as a function of anodization time for samples annealed at $450^{\circ} \mathrm{C}$.

\subsubsection{Effect of calcination temperature}

It is well demonstrated that the temperatures where the transition from amorphous $\mathrm{TiO}_{2}$ to anatase and then to rutile takes place, are strongly related with numerous factors such as the synthetic pathway, the presence of exogenous ions, and the calcination atmosphere $[28,29,36-39]$.

Our previous study [26] has shown that as-anodized TNTAs are amorphous, while crystalline $\mathrm{TiO}_{2}$ is present only after annealing. Here we investigated the effect of calcination temperature on the structural characteristics of TNTAs. Ti webs were anodized for $1 \mathrm{~h}$ and then annealed under oxygen at different temperatures, between 400 and $600^{\circ} \mathrm{C}$. When the Ti web was treated at temperatures above $600^{\circ} \mathrm{C}$ the structure of the substrates becomes mechanically unstable i.e. the junctions between the microfibers due to volume expansion lose their interconnection and very easily break. Samples treated at $650^{\circ} \mathrm{C}$ were very fragile so evaluation as photoelectrodes was not possible.

Fig. 5a shows SEM images of the self-organized, highly ordered TNTAs as-anodized and after annealing at various temperatures. The SEM images indicate that there was no delamination of the nanotube arrays from the Ti microfiber surface. This delamination was very significant (Fig. 5b) when the anodization process was realized with fresh solution. This is due to fast formation of the TNTAs which then causes lateral interactions and thus form cracks on the surface of the Ti microfibers. It is reported [31] that the aging of the solution improves the structural stability of the anodized samples and as one can see there is no significant change between the as-anodized samples and the samples after $\mathrm{O}_{2}$ annealing.

Fig. 6a shows the XRD patterns of the anodized samples after calcination at different temperatures. The XRD analysis showed that in the TNTAs calcined at 400 and $450^{\circ} \mathrm{C}$, the only $\mathrm{TiO}_{2}$ phase is anatase. As the calcination temperature increases above $500^{\circ} \mathrm{C}$, rutile peaks starts to appear and become significant at $600^{\circ} \mathrm{C}$. The results of our study show that the TNTAs developed by anodization of a curvy 
Ti-web exhibit similar characteristics to those developed by anodized flat Ti foils [38-41]. Increase in the relevant amount of rutile upon annealing at higher temperatures has been also reported by Hardcastle et al. [39] and Jarosz et al. [42] for the case of TNTAs developed by anodization of Ti foils. Moreover, Xu et al. [24] found that the intensity of the rutile peaks strongly depends on the length of the TNTAs. They observed rutile was present only in TNTAs with length of 0.8-1.2 $\mu \mathrm{m}$, while only the anatase phase in longer TNTAs, which is similar to our case (where TNTAs were developed by anodization of a Ti web).
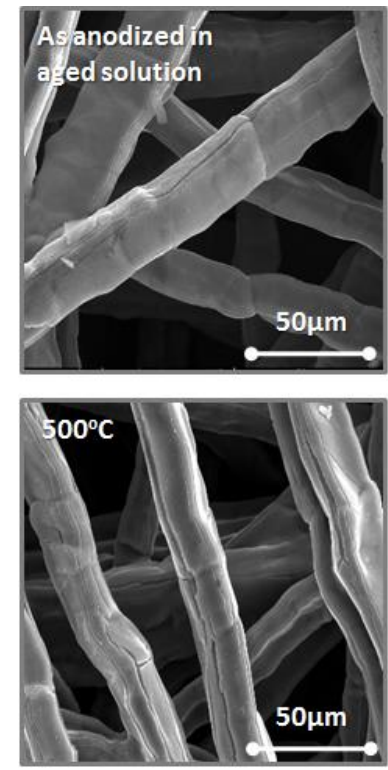
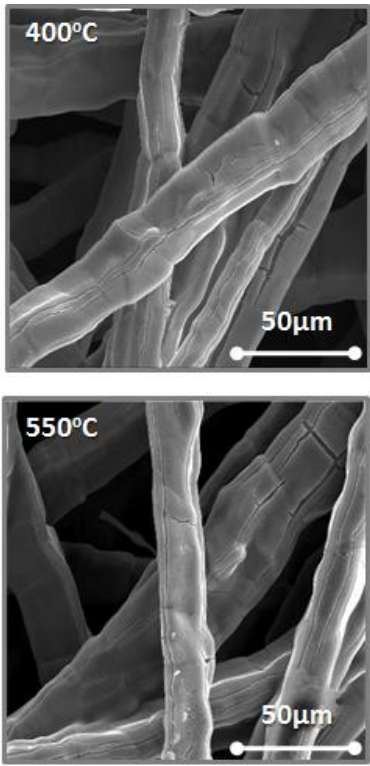

(a)
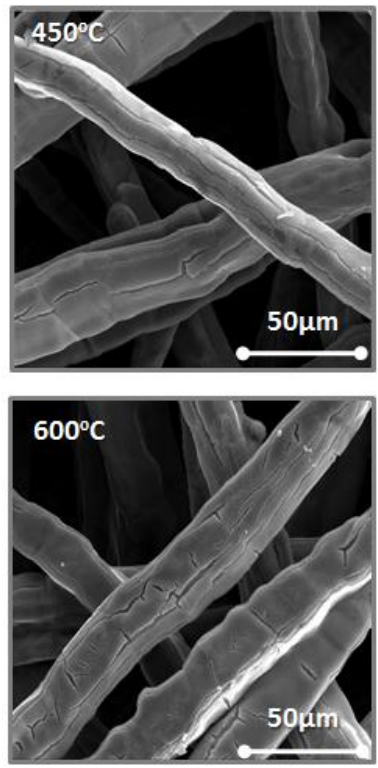
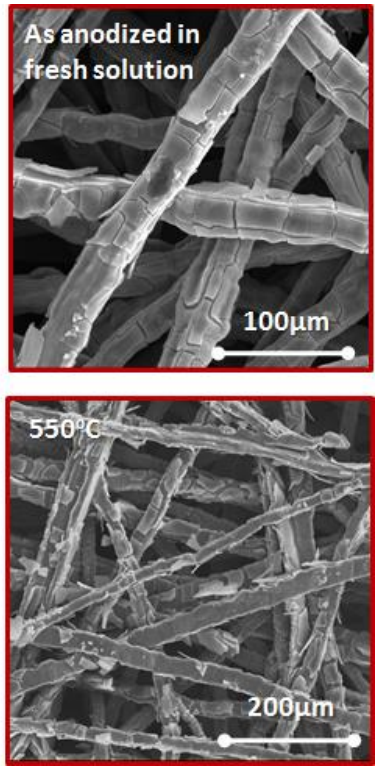

(b)

Fig.5 SEM images of TNTAs (a) in aged and (b) fresh solution before and after annealing at different temperatures.

For comparison, we followed the same annealing procedures on both classes of photoanodes, TNTAs and $\mathrm{TiO}_{2}$ layers. In the XRD patterns of the $\mathrm{TiO}_{2}$ layers (Fig. $6 \mathrm{~b}$ ), the titanium peaks of the unmodified $\mathrm{Ti}$ web are dominant. Small amounts of crystalline $\mathrm{TiO}_{2}$ corresponding to the rutile phase were detected only at annealing temperatures higher than $500^{\circ} \mathrm{C}$ and increased with the calcination temperature, while the anatase phase does not appear in these samples. This indicates that the oxide layer at annealing temperatures below $500^{\circ} \mathrm{C}$ is below the detection limit of XRD. Table S1 summarizes the XRD parameters including the full width at half maximun (FWHM), the peak intensity, the rutile:anatase intensity ratio and the crystalline grain size of anatase and rutile. The morphology of the Ti substrate, which is consisted of a web microfibers, does not allow the exact quantification of the included parameters and thus, they serve as a qualification guideline.

In further analysis we conducted Raman spectrometry for obtaining insights about the physicochemical structure. Raman spectra of the TNTAs are shown in Fig. 7a. The major peaks of anatase at 144, 197, 398, 515 and $638 \mathrm{~cm}^{-1}$ are evident in all the samples in good agreement with literature [36-39]. The characteristic peaks of rutile starts to appear when photoanodes are annealed at temperatures above $500^{\circ} \mathrm{C}$. In these spectra there are overlaps between the anatase and rutile peaks (in the range of $\left.400-650 \mathrm{~cm}^{-1}\right)$ and only at $600^{\circ} \mathrm{C}$ the two peaks of rutile around $447 \mathrm{~cm}^{-1}\left(\mathrm{E}_{\mathrm{g}}\right.$ mode) and $612 \mathrm{~cm}^{-1}\left(\mathrm{~A}_{1 \mathrm{~g}}\right.$ mode) are very intense while at $243 \mathrm{~cm}^{-1}$ a broad peak is formed again in good agreement with literature [37-40]. 
Raman spectroscopy of the $\mathrm{TiO}_{2}$ layers (annealed at different temperatures) clearly demonstrates that rutile phase is evident mainly at 243,447 and $612 \mathrm{~cm}^{-1}$ even at $400^{\circ} \mathrm{C}$ and becomes more evident as the annealing temperature is increased. These findings are in good agreement with similar studies in anodized and untreated foils $\mathrm{O}_{2}$ annealed at various temperatures [38-41].
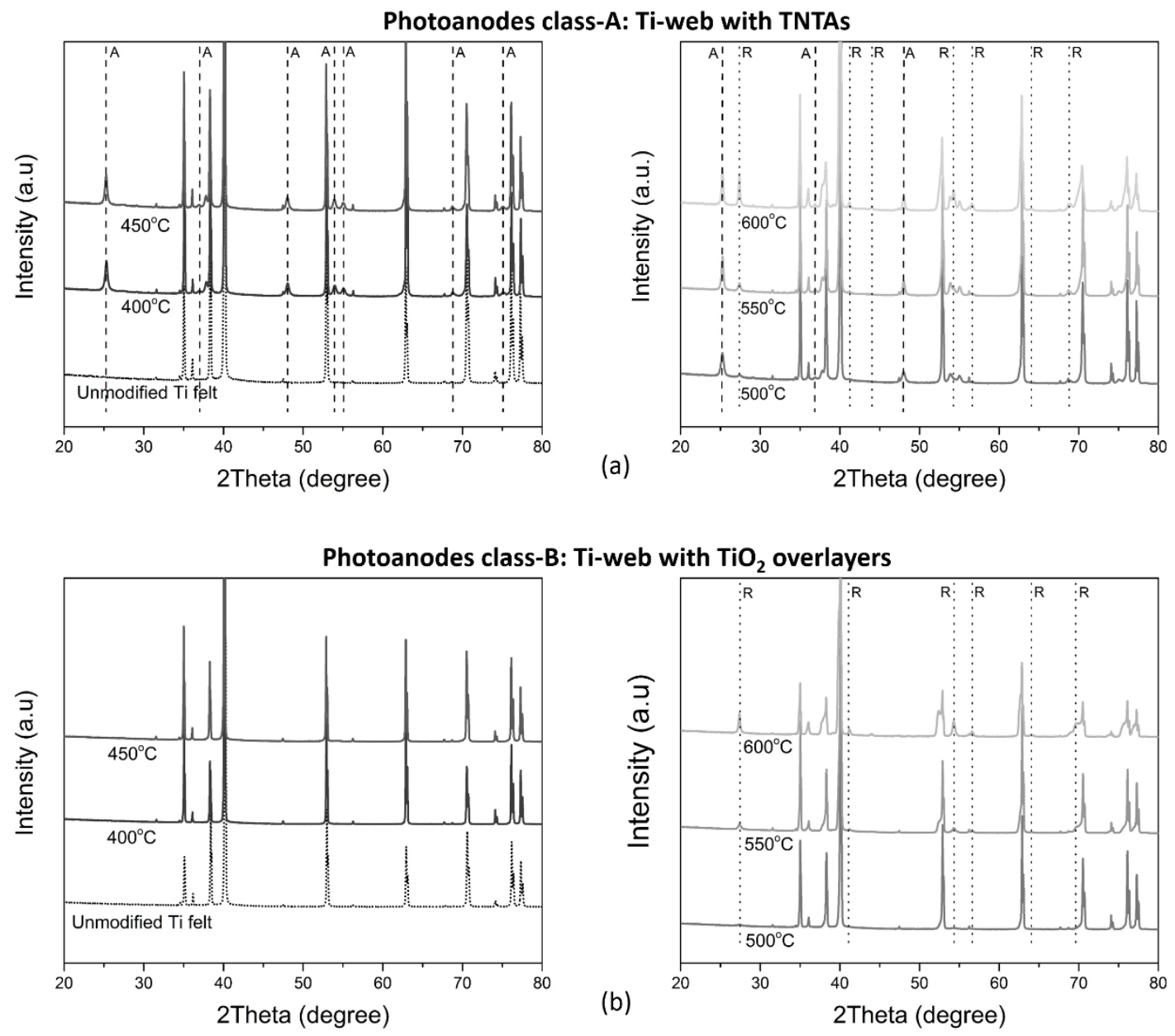

Fig.6 XRD pattern of (a) TNTAs after anodization at $30 \mathrm{~V}$ for $1 \mathrm{~h}$ and (b) $\mathrm{TiO}_{2}$ layers annealed at different temperatures for $5 \mathrm{~h}$ in air.
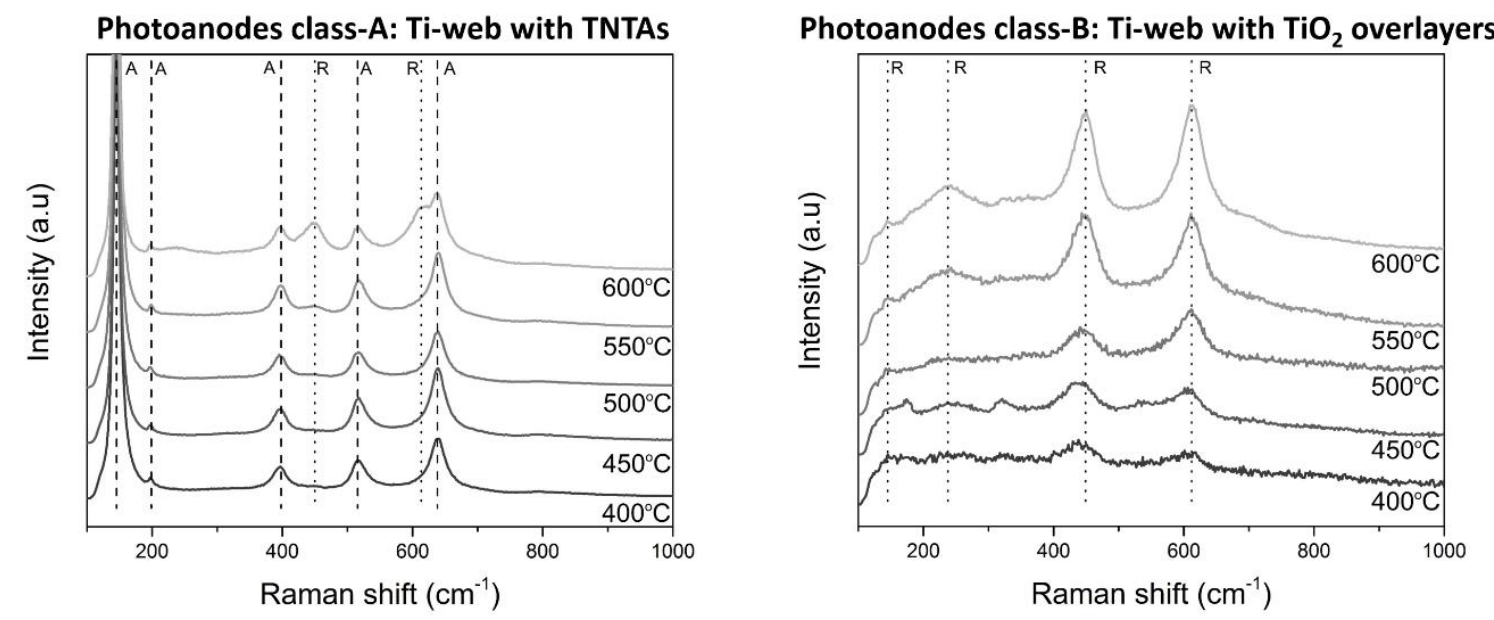

Fig.7 Raman spectra for anodized (TNTAs) and non-anodized $\left(\mathrm{TiO}_{2}\right.$ layers) annealed at different temperatures in air for $5 \mathrm{~h}$. 
An analysis of peak position and width of the rutile modes based on phonon confinement model [4245] demonstrates a clear shift of these modes to higher wavenumbers with a reduced width as a function of increasing temperature. This trend is a feature of size-dependent property of rutile grains. At low temperature grains are smaller, and as the temperature increases, the grain size increases and the peak positions appear close to the peak position of bulk rutile $[43,44]$. The analysis of rutile $\mathrm{E}_{\mathrm{g}}$ mode revealed that, with an increasing annealing temperature, the peak position shifts from $438 \mathrm{~cm}^{-1}$ to $449 \mathrm{~cm}^{-1}$ in parallel with a decrease of the peak width from $61 \mathrm{~cm}^{-1}$ to $41 \mathrm{~cm}^{-1}$. In a similar fashion, the position of $A_{1 \mathrm{~g}}$ mode shifts from $606 \mathrm{~cm}^{-1}$ to $612 \mathrm{~cm}^{-1}$ and its width decreases from $54 \mathrm{~cm}^{-1}$ to 39 $\mathrm{cm}^{-1}$. The estimated grain sizes of rutile phase are in the range of $2.5 \mathrm{~nm}$ to $10 \mathrm{~nm}$ with increasing annealing temperature.

\subsection{Photoanode performance in conventional PEC cells based on aqueous electrolytes}

\subsubsection{Photoelectrochemical activity for water splitting}

After $\mathrm{O}_{2}$ annealing, both classes of photoanodes were used for the photoelectrochemical water splitting in $0.1 \mathrm{M} \mathrm{H}_{2} \mathrm{SO}_{4}$ solution. The photocatalytic activity was evaluated under chopped illumination using an UV-LED lamp. The current was recorded while the potential between the working and the reference electrode was linearly varied between 0 and $1.5 \mathrm{~V}$ with a scan rate of $2.5 \mathrm{mV} \mathrm{s}^{-1}$. This value was chosen due to the character of the experiment which requires us to proceed with slow scan rates $\left(<5 \mathrm{mV} \mathrm{s}^{-1}\right)$ as indicated by $\mathrm{Xu}$ et al [45].

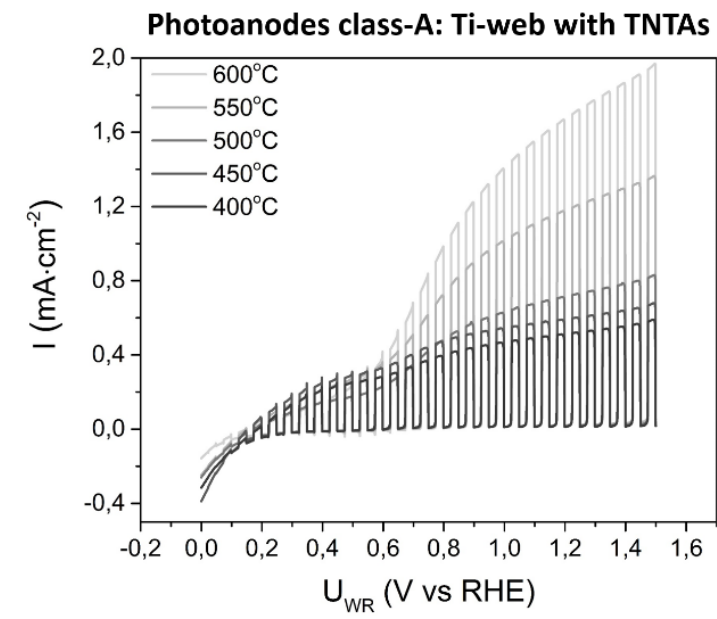

(a)

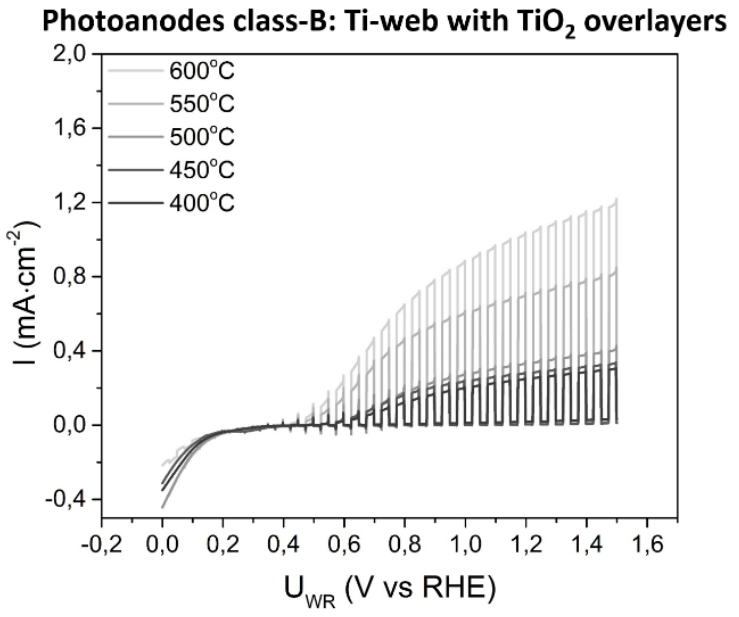

(b)

Fig.8 Linear voltammetry sweeps $\left(2.5 \mathrm{mV} \cdot \mathrm{s}^{-1}\right)$ under chopped illumination for water splitting on (a) TNTAs and (b) $\mathrm{TiO}_{2}$ layers, in an aqueous electrolyte $\left(0.1 \mathrm{M} \mathrm{H}_{2} \mathrm{SO}_{4}\right)$.

Fig. 8 presents the linear sweep voltammograms (LSVs) under chopped illumination for both classes of photoanodes. Negligible currents are recorded for all samples upon turning the illumination off within the whole potential range. A strong dependence between photoactivity and calcination temperature was found in all cases. The onset of photocurrent for anodized samples (TNTAs) starts already at $\sim 0.1$ $\mathrm{V}$ vs RHE while for $\mathrm{TiO}_{2}$ layers the onset shifts at much higher potentials, between $0.4 \mathrm{~V}$ and $0.6 \mathrm{~V}$ vs RHE. The effect of the annealing temperature on the onset potential is negligible for TNTAs; however, for the $\mathrm{TiO}_{2}$ layers the onset potential is decreased from $0.6 \mathrm{~V}$ to $0.4 \mathrm{~V}$ vs $\mathrm{RHE}$ as the annealing temperature is increased from 400 to $600^{\circ} \mathrm{C}$. These results are summarized in Table S2, where the effect of annealing temperature on the photocurrent at $1.23 \mathrm{~V}$ vs RHE as well as the onset potential are presented. 
The LSVs of the TNTAs are presented in Fig.8a and consist of two regions. At the low polarization region $(<0.55 \mathrm{~V})$ the photoactivity reaches a first plateau and only slightly decreases as the annealing temperature increases. At $\sim 0.55 \mathrm{~V}$ an abrupt increase in the photocurrent is observed, which becomes more pronounced as the annealing temperature increases. In the high polarization region $(>0.55 \mathrm{~V})$ the photocurrent is largely affected by the annealing temperature in a manner that increased photoactivity is observed with the samples annealed at higher temperatures. At $1.5 \mathrm{~V}$, maximum photocurrents of $\sim 2.0$ and $1.2 \mathrm{~mA} \mathrm{~cm}^{-2}$ were obtained with TNTAs calcined at $600^{\circ} \mathrm{C}$ and $400^{\circ} \mathrm{C}$ respectively. As already discussed, annealing the anodized samples at different temperatures leads to materials with different rutile:anatase ratios. Thus, the shape of the voltammograms can be possibly explained by an overlapping of the photoactivities from the anatase and the rutile phase, with the first one dominating at low polarization $(<0.55 \mathrm{~V})$ and the later dominating at higher polarization $(>0.55 \mathrm{~V})$. This behaviour is also evident in the $\mathrm{TiO}_{2}$ layers, in which the only contribution to the observed current comes from the rutile phase ( $>0.55 \mathrm{~V}$ region).

The effect of annealing temperature on the photocatalytic activity of TNTAs from anodized Ti foil or mesh has been investigated in the literature with contradictory results reported. The results of $\mathrm{Li}$ et al. [15] and Sun et al. [47] suggest an optimal calcination temperature of $450^{\circ} \mathrm{C}$, which the authors attributed to the excellent crystallization and well-ordered nanostructures obtained at this treatment. On the other hand, other studies $[39,48,49]$ have shown an increase in photoactivity with even higher annealing temperatures and attributed this behaviour to the enhanced charge transfer due to increased crystallinity. A recent study of Ali et al. [50] indicated that anatase TNTAS grown during Tifoil anodization are more active for the photoelectrochemical water splitting when decorated with rutile, thus showing a synergetic anatase-rutile effect. This synergy is also highlighted in a recent work [51] where the highly photocatalytic active form is observed for mixed phase of two polymorphs anatase and rutile rather than for their pristine compositions. Such a synergetic effect is understood by the staggered band alignment favourable to spatial charge separation.

The shape of the LSVs in our study suggests that reliable comparisons between anodized Ti-webs should be made only at similar potential values. Moreover, according to Xu et al. [24], LSVs under chopped illumination with anodized Ti foils do not show any shape changes at a threshold potential value, as observed at $\sim 0.55 \mathrm{~V}$ in our case. The controversial findings may arise from the fact that different protocols for the anodization were followed by several groups. As depicted in Fig. $5 b$ the anodization conditions can strongly affect the delamination of the electrode after annealing, which in turn affects the photoelectrode activity. Thus, comparisons of the activity and relations with crystallinity can only be valid if the experimental results are accompanied by SEM images which verify the absence of delamination in the samples.

In order to verify the promoting role of anatase phase for the photoelectrochemical water splitting using TNTAs from anodized $\mathrm{Ti}$ web, photoelectrochemical characterization was carried out using $\mathrm{TiO}_{2}$ layers (Fig.8b). Similarly to the anodized samples, two regions in the LSVs were also observed in the case of $\mathrm{TiO}_{2}$ layers with the transition happening again at $\sim 0.5 \mathrm{~V}$. At applied potential values higher than $0.5 \mathrm{~V}$, the photoactivity increases with the calcination temperature, with a maximum photocurrent of $1.2 \mathrm{~mA} . \mathrm{cm}^{-2}$ at $1.5 \mathrm{~V}$ for the sample calcined at $600^{\circ} \mathrm{C}$. According to the crystallographic data (Fig.6b), annealing of the Ti webs at higher temperature leads to the increase of crystal grain sizes, and appearance of a higher crystalline rutile phase compared to lower temperatures, confirming that this phase is responsible for the enhanced activity for water splitting. 
Comparing the activity of the two classes of photoanodes, photocurrents obtained with TNTAs are up to 2 times larger than those obtained with $\mathrm{TiO}_{2}$ layers. Taking into account that the surface area of anodized samples is $\sim 30$ times larger than that of non-anodized samples, it seems that $\mathrm{TiO}_{2}$ layers exhibited unexpectedly high activity. This is most likely related with the faster charge separation/transfer due to the thin $\mathrm{TiO}_{2}$ layers that developed after the $\mathrm{O}_{2}$ annealing on the $\mathrm{Ti}$ microfiber surface. On the other hand, at applied potentials below $0.5 \mathrm{~V}, \mathrm{TiO}_{2}$ layers are totally inactive, unlike the modest photoactivity which was observed with TNTAs in this potential region. This is related to the fact that anatase phase was not detected in these samples (Fig. 6b).

The superior photoactivity of anatase compared to rutile is generally accepted and according to recent studies it can be attributed to differences in the diffusion length, rate of recombination, energetic distribution and transport mechanism of the charge carriers [52,53]. Literature findings suggest a different dependence between film thickness and photocatalytic activity of the two $\mathrm{TiO}_{2}$ polymorphs, showing that charge carriers excited deeper in the bulk of anatase contribute to the surface reactions and account for a larger material-volume which contributes to photocatalytic activity. These findings suggest that comparison between the two families of photoanodes in our study is not straightforward due to the different geometry of the samples (nanotubes vs thin layers).

\subsubsection{Photoelectrochemical activity for (poly)alcohol oxidation}

Majority of the work employing PEC studies with anodized TNTAs deals with water splitting. However, it is well established in literature that $\mathrm{TiO}_{2}$ exhibits higher efficiency for hydrogen production in the presence of a sacrificial agent. Using organic sacrificial agents, such as alcohols, higher photocurrents and smaller onset potentials have been reported $[12,14,17,38]$. To this end, we investigated the effect of annealing temperature on the photoelectrochemical activity of anodized and untreated samples during (poly)alcohol oxidation. Special attention is given in the case of hydrogen production via ethanol photo-oxidation due to its renewable character that ensures sustainability and $\mathrm{CO}_{2}$ neutrality $[54,55]$.

Fig. 9 compares the LSVs obtained in presence and in absence of $0.1 \mathrm{M}$ ethanol under chopped illumination. This low concentration was selected to simulate waste water treatment where small quantities of organics are present. For all photoanodes, the obtained dark current is close to zero between 0.2 and $1.5 \mathrm{~V}$ vs RHE and it becomes negative at potentials lower than $0.2 \mathrm{~V}$ vs RHE. Comparing the activity of TNTAs, the current increases in presence of ethanol. This increase is generally attributed to: (a) continuous scavenging of photoholes by ethanol which leads to suppression of charge recombination and enhancement of surface oxidation, (b) the current doubling effect $[12,14,17,37,38,56]$.Two main features were observed in Fig. 9a. First, the ethanol-induced enhancement in photoactivity was more pronounced for samples annealed at lower temperatures. Second, even though the current enhancement exists within the whole investigated potential range, it was more pronounced at lower polarization. For instance, with the TNTAs annealed at $450^{\circ} \mathrm{C}$, a twofold increase in current was obtained in presence of ethanol at $1.5 \mathrm{~V}$ vs RHE, while a three-fold increase was obtained at $0.3 \mathrm{~V}$ vs RHE. The correlation between the photocurrent enhancement upon the ethanol addition and the annealing temperature is presented in Table S3 (for both classes of photoanodes at $1.23 \mathrm{~V}$ vs RHE).

Taking into account the findings of the physicostructural characterization (Fig. 6 and 7), it appears that the anatase phase, which is predominant at TNTAs annealed at temperatures below $500^{\circ} \mathrm{C}$, is mainly responsible for the photoelectrocatalytic activity for ethanol oxidation. Moreover, as discussed in section 2.1 , the photoactivity of anatase is more dominant at the low polarization region, which 
accounts for the observed higher current increase in presence of ethanol at low potentials. As the calcination temperature increases, the relative amount of rutile increases, leading to a decrease in activity for ethanol oxidation. This assumption is further supported by the experimental results obtained with the $\mathrm{TiO}_{2}$ layers, where rutile was the only detected crystalline phase. As shown in Fig. $9 b$, identical LSVs were recorded both in absence and in presence of ethanol with the $\mathrm{TiO}_{2}$ layers. This observation indicates negligible activity of rutile for ethanol oxidation at these experimental conditions. Finally, the strong influence of rutile on the photoactivity of TNTAs indicates that rutile is present at the surface of $\mathrm{TiO}_{2}$ nanotubes, and thus in the interface with the liquid phase.
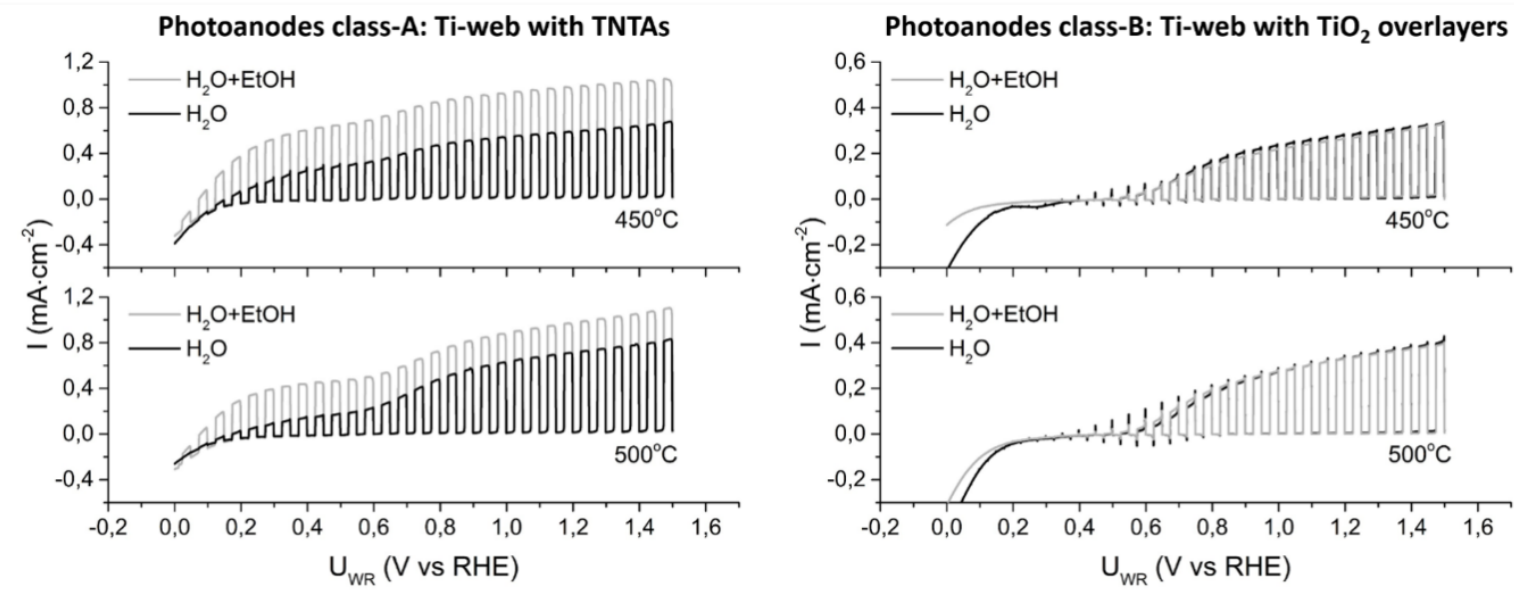

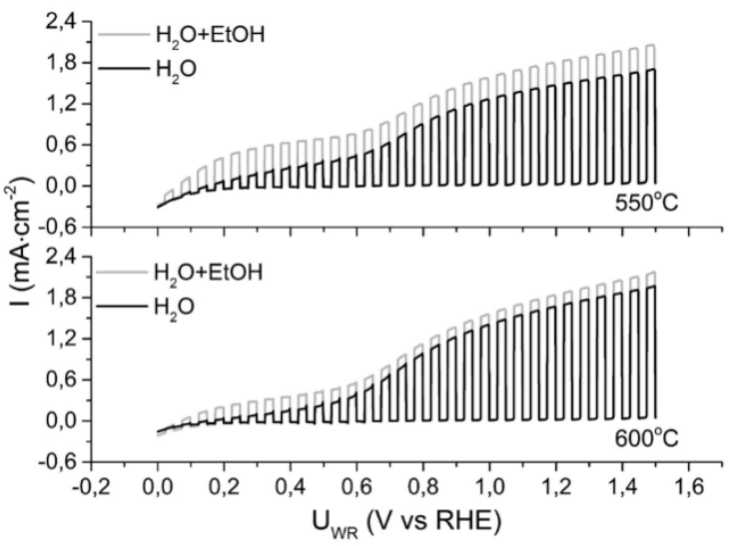

(a)

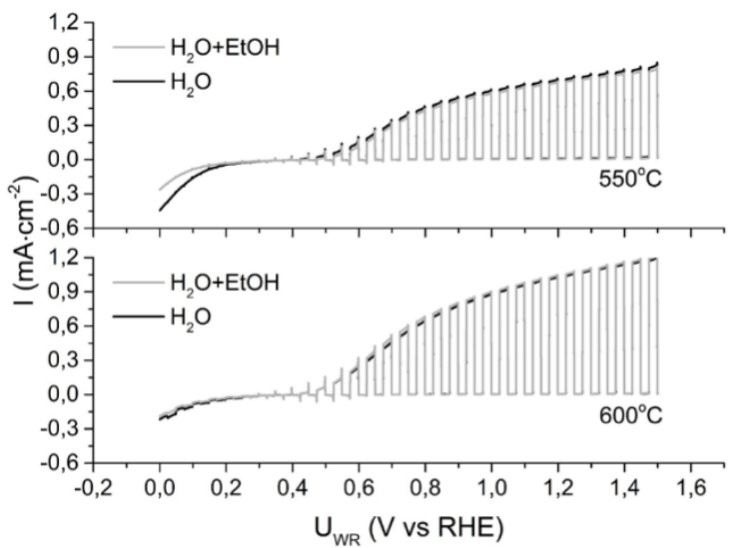

(b)

Fig. 9 Linear voltammetry sweeps $\left(2.5 \mathrm{mV} \mathrm{s}^{-1}\right)$ under chopped illumination for ethanol and water photo-oxidation on (a) TNTAs and (b) $\mathrm{TiO}_{2}$ layers treated at various annealing temperatures, in an aqueous electrolyte $\left(0.1 \mathrm{M} \mathrm{H}_{2} \mathrm{SO}_{4}\right.$ and $\left.0.1 \mathrm{M} \mathrm{EtOH}\right)$. The black line depicts the performance of the photoanode for water oxidation while the grey line illustrates the performance in the presence of ethanol.

Veres et al. [56] investigated the relationship between the $\mathrm{TiO}_{2}$ structure and the photocatalytic properties during hydrogen production from ethanol vapour and also reported a decrease in the activity of rutile-rich samples. The different behaviour between anatase and rutile phases during the photocatalytic oxidation of organic molecules has been also reported by other groups $[37,38,40,58,59]$ showing that the rutile phase can be active or inactive for the photocatalytic oxidation of phenol according to the preparation methods. According to the authors of this study, this variability in photoreactivity can be related to either to kinetic factors (since the preparation method affects the physicochemical characteristics) or to the presence of surface $\mathrm{OH}^{-}$groups (which affects significantly 
the charge separation). A detailed analysis of the role of the $\mathrm{TiO}_{2}$ phase on the ethanol photo-oxidation necessitates DFT calculations; such a theoretical study is in progress and will be the subject of an upcoming publication.

Further, we investigated the effect of using other sacrificial agents in the solution. Specifically, the cases of methanol, iso-propanol and glycerol were examined and the corresponding experimental results are presented in Fig. 10 for TNTAs and $\mathrm{TiO}_{2}$ layers annealed at $450^{\circ} \mathrm{C}$. Similarly to the results with ethanol, a significant enhancement in the photocurrent is observed under illumination in presence of all the organic compounds, only with the anatase and anatase-rutile containing samples (anodized TNTAs). In the presence of (poly)alcohols and at applied voltages higher than $0.8 \mathrm{~V}$, the photocurrent reaches a limiting value, which corresponds to the highest electron-hole separation due to the depletion of electrons in the space charge region by the positive applied potential [59]. Moreover, our results indicate that the use of ethanol and methanol as sacrificial agents is more beneficial than the use of iso-propanol or glycerol, which is probably related with adsorption and electrokinetic effects [60]. The correlation between the photocurrent enhancement (at 1.23V vs RHE) upon different additives for the photoanodes annealed at $450^{\circ} \mathrm{C}$ is presented in Table S4.

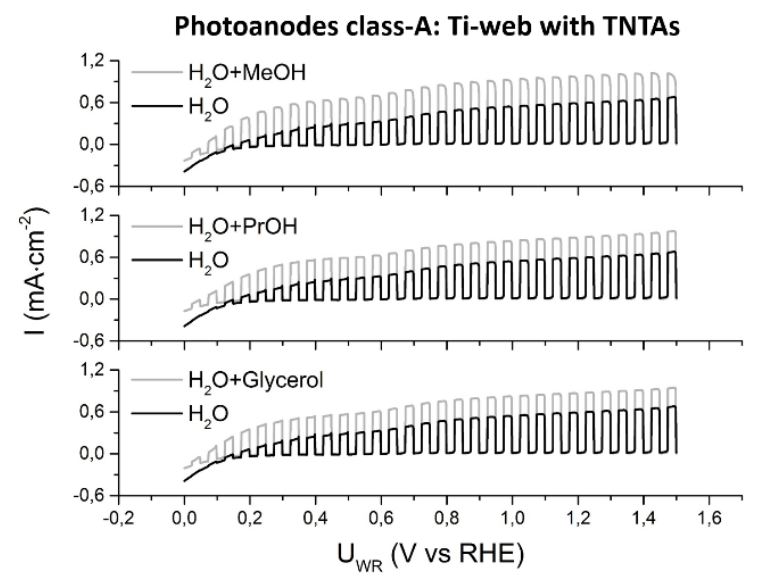

(a)

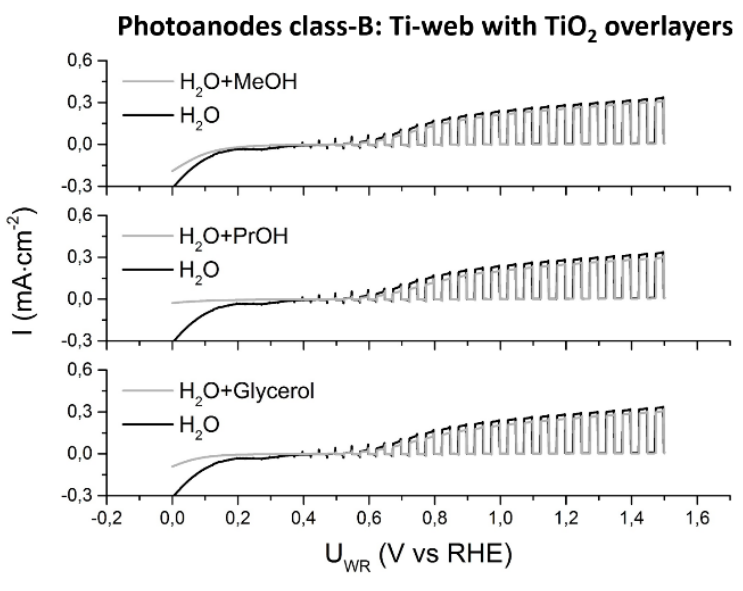

(b)

Fig. 10 Linear voltammetry sweeps $\left(2.5 \mathrm{mV} \mathrm{s}^{-1}\right)$ under chopped illumination for methanol, isopropanol, glycerol and water photo-oxidation on (a) TNTAs and (b) $\mathrm{TiO}_{2}$ layers annealed at $450^{\circ} \mathrm{C}$, in an aqueous electrolyte $\left(0.1 \mathrm{M} \mathrm{H}_{2} \mathrm{SO}_{4}\right.$ and $0.1 \mathrm{M}$ organic additives). The black line depicts the performance of the photoanode for water oxidation while the grey line illustrates the performance in the presence of the organic phase.

\subsection{Photoelectrochemical activity for water splitting in PEM-PEC cells - Gas phase operation}

The best performing TNTAs and $\mathrm{TiO}_{2}$ layers were also evaluated as photoanodes for water splitting during gas phase operation. In this case the photoanodes were interfaced onto polymeric electrolyte membranes with either proton $\left(\mathrm{H}^{+}\right)$or hydroxide ion $\left(\mathrm{OH}^{-}\right)$conductivity and then were introduced in a PEM-PEC reactor (Fig.2). A low water vapour pressure of $3.5 \mathrm{kPa}$ was supplied by flowing a carrier gas through a thermostated gas saturator filled with deionized water. Two cases were investigated for the nature of the carrier gas; helium was used as an inert carrier gas and air was used in order to simulate water capture from ambient air $[19,20,26]$. The performance of the photoanodes utilizing proton and hydroxide ion conducting membrane is depicted in Fig. $11 \mathrm{a}, \mathrm{b}$ and c, d respectively. For comparison we have performed LSV experiments of the same photoanodes with aqueous electrolytes in 
"equivalent" conditions i.e. $\mathrm{pH}=1$ and $\mathrm{pH}=13$ to mimic $\mathrm{H}^{+}$and $\mathrm{OH}^{-}$conducting membranes respectively $[31,34]$. These LSV curves are also displayed in Fig. 11 and are denoted as liquid phase.

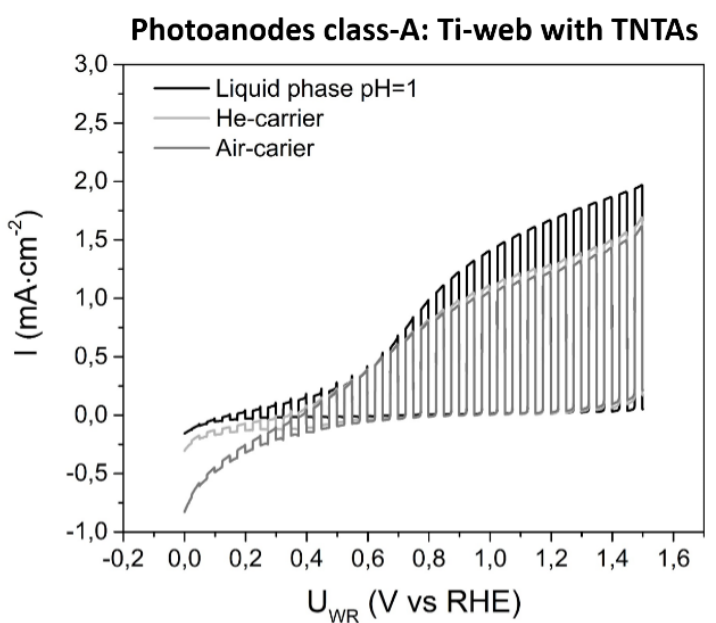

(a)

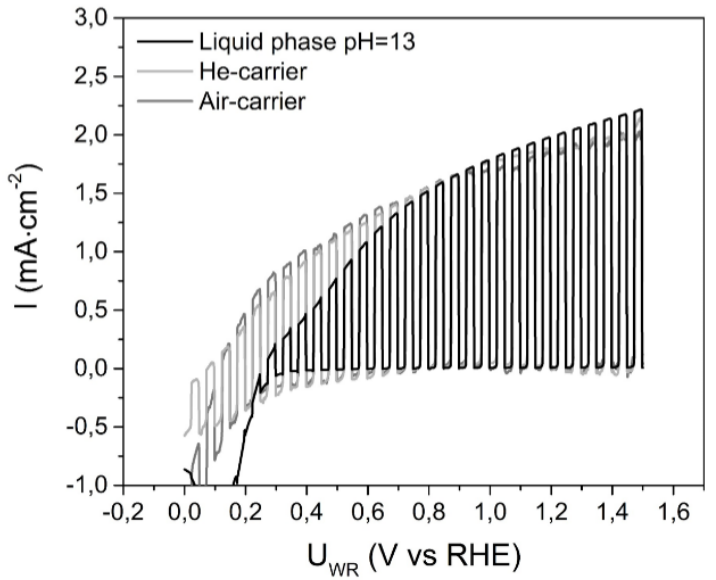

(c)

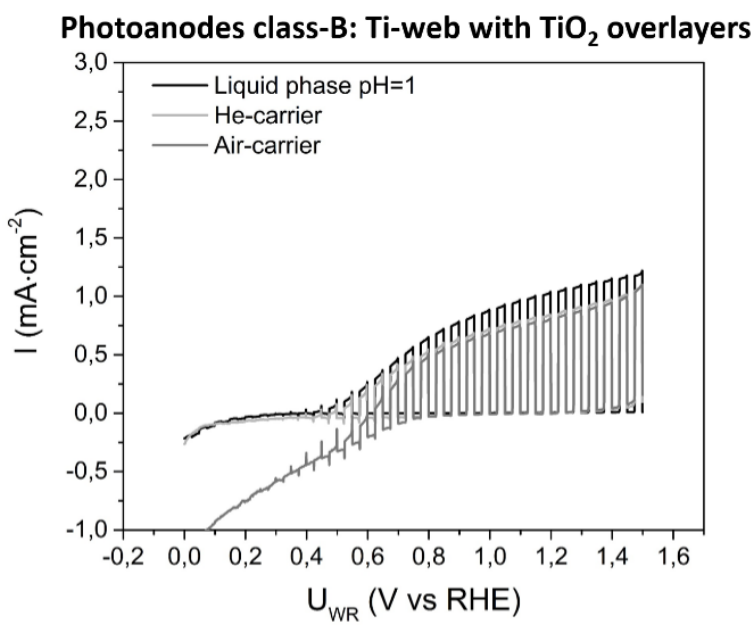

(b)

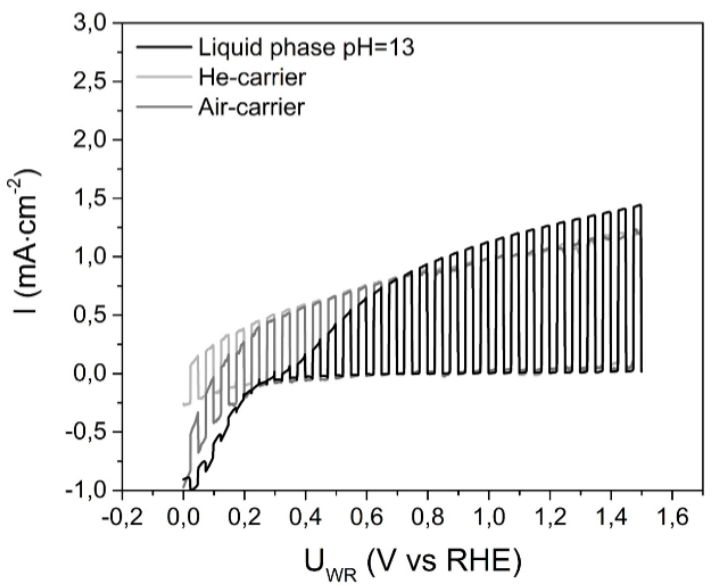

(d)

Fig. 11 Linear voltammetry sweeps $\left(2.5 \mathrm{mV} \mathrm{s}^{-1}\right)$ on the TNTAs and $\mathrm{TiO}_{2}$ layers photoanode annealed at $600^{\circ} \mathrm{C}$ under chopped illumination for water splitting in conjunction with $(a, b)$ proton conducting membrane (Nafion 117) and (c,d) hydroxide ion conducting membrane [30,31]. Grey lines correspond to gas phase operation with $\mathrm{He}$ (light grey line) and air (dark grey line) carrier gases for $3 \mathrm{kPa} \mathrm{H}_{2} \mathrm{O}$. The black line corresponds to operation with aqueous electrolyte at $(a, b) p H=1\left(0.1 \mathrm{M} \mathrm{H}_{2} \mathrm{SO}_{4}\right)$ and $(c, d)$ $\mathrm{pH}=13(0.1 \mathrm{M} \mathrm{KOH})$.

As illustrated in Fig. 11, both TNTAs and $\mathrm{TiO}_{2}$ layers show a common trend that is the nature of the carrier gas has an important effect on the activity only at low polarization. Specifically, with the $\mathrm{H}^{+}$ conducting electrolyte, a significant deviation between the LSV curves obtained with $\mathrm{He}$ and air was observed at potentials below $0.4 \mathrm{~V}$ with the TNTAs and below $0.6 \mathrm{~V}$ with the $\mathrm{TiO}_{2}$ layers. With the $\mathrm{OH}^{-}$ conducting membrane the nature of the carrier gas has an effect only at low potentials ( $<0.2 \mathrm{~V} v \mathrm{RHE}$ ). At the region of low polarization the oxygen molecules (for the case of using air as the carrier gas) act as mediators for recombination and this cause back reactions which deteriorate photoefficiency. As discussed in our previous paper [26], the detrimental impact of oxygen is minimized at higher potentials, where the fast electron injection inside the $\mathrm{TiO}_{2}$ valence band limits the possible recombination pathway $[19,20]$. The shift of the threshold potential at lower values for the case of anodized samples could be attributed to the nanostructured characteristics of these samples. 
The activity of both classes of photoanodes was higher in alkaline environment (liquid or $\mathrm{OH}^{-}$ conducting membrane) compared to acidic environment (liquid or $\mathrm{H}^{+}$conducting membrane), which can be ascribed to reduced recombination phenomena. According to Arico et al. [32] this is related with the large concentration of $\mathrm{OH}^{-}$species at the interface between the photoanode and the alkaline electrolyte the alkaline environment, which favours the capture of holes. Table S5 summarizes the photon to hydrogen efficiencies for both photoelectrodes at $1.23 \mathrm{~V}$ vs RHE for conventional PEC and PEM-PEC operations.

The performance of the photoanodes in gas phase operation in our PEM-PEC cell with the $\mathrm{H}^{+}$ conducting electrolyte is very close to the ones obtained in conventional $\mathrm{PEC}$ cells at $\mathrm{pH}=1(0.1 \mathrm{M}$ $\mathrm{H}_{2} \mathrm{SO}_{4}$ ). The photocurrent in gas phase was 1.22 and $1.19 \mathrm{~mA} \cdot \mathrm{cm}^{-2}$ at $1.23 \mathrm{~V}$ vs RHE when He or air are used as carrier gas respectively. These values correspond to $74 \%$ and $71 \%$ of the current obtained at the same potential in conventional PEC cells at $\mathrm{pH}=1$. This is a very interesting observation taking into account that only $3 \%$ water vapour during gas phase PEM-PEC operation can result to more than $70 \%$ of the photocurrent of conventional PEC cells operating with aqueous electrolytes and reactants. Both classes of photoanodes are very stable as depicted in Fig. S3. It is observed that even since after $12 \mathrm{~h}$ of operation and 50 cycles of light on and off operation the performance is slightly affected and the derived photocurrent decreases less than $8 \%$ and $4 \%$ for titania nanotubes and overlayers respectively.

The results are even more promising when utilizing a hydroxide ion conducting membrane (Fig. 11c, d). Gas phase operation with the $\mathrm{OH}^{-}$conducting membrane is much better in the low potential range in comparison with the liquid operation of conventional PEC cells at $\mathrm{pH}=13(0.1 \mathrm{M} \mathrm{KOH})$. The onset potential for liquid phase operation at $\mathrm{pH}=13$ is $0.2 \mathrm{~V}$ vs $\mathrm{RHE}$, while for the case of gas phase operation the photogenerated species are present in the whole potential range under examination (i.e. 0-1.5 V vs RHE). Gas phase operation in PEM-PEC cell is superior compared to the conventional cells up to 0.9 $\checkmark$ vs RHE while at higher polarization the obtained photocurrent of conventional PEC cells are $5-10 \%$ better

These results give, for the first time, a comparison between the performance of a photoelectrode in a PEM-PEC operating with proton and hydroxide ion conducting membranes vs a conventional PEC cell operating at $\mathrm{pH}=1$ or $\mathrm{pH}=13$ respectively. Regarding the photon to hydrogen efficiency, the utilization of a hydroxide ion membrane enhances the performance of the photoelectrode in comparison with conventional PEC cells (performed in either acidic or alkaline conditions) and with the PEM-PEC cells operated with proton conducting membranes (Table S5). This comparison is essential for the development of future gas phase PEM-PEC installations. Water management when scaling up PEC systems would be much simpler in gas phase operation than in the case of conventional aqueous electrolyte PEC cells, which require a pumping system. It can be achieved either via a carrier gas passing through a thermostated water saturator or via natural convection for capturing the water molecules contained in the ambient air $[19,20,26]$.

\section{Conclusions}

In our study we utilize a new type of substrate for photoanodes which is suitable for our newly developed polymeric electrolytic membrane photoelectrochemical (PEM-PEC) cells. This substrate consists of a Ti web of microfibers and we have found that a simple thermal treatment under oxygen atmosphere of these (untreated) substrates could provide $\mathrm{TiO}_{2}$ photoanodes with surprisingly good performances for water oxidation. Electrochemical anodization of these substrates leads to formation 
of $\mathrm{TiO}_{2}$ nanotube arrays which boosts the surface area of the substrates by a factor of 30 . The anodization current profile is correlated with the stages of nanotube formations. The effect of temperature annealing is examined in both classes of photoanodes and it is beneficial when photoanodes are evaluated for water oxidation. The performance of the photoanodes for (poly)alcohols oxidation is strongly related with the ratio of anatase vs rutile. The most efficient photoanodes for organic oxidation are the ones in which anatase is the predominant phase. The best performing photoanodes were evaluated in our PEM-PEC cells in gas phase operation mode. Photoanodes were investigated in conjunction with a proton or a hydroxide ion conducting membrane electrolyte. The performance in both cases is very promising taking into account the cost reduction of gas phase PEM-PEC cell operation, arising from the lack of a liquid pumping systems. Moreover, it was demonstrated, for the first time, that the observed photocurrent in gas phase operation when hydroxide ion conducting membrane is utilized in the PEM-PEC cells is superior to the conventional (liquid phase) operation at $\mathrm{pH}=13$ for water splitting.

\section{Acknowledgments}

This work is part of the programme ' $\mathrm{CO}_{2}$-neutral fuels' Grant No. 700.001.516.50, of NWO-I, formerly known as the Foundation for Fundamental Research on Matter (FOM), which is financially supported by the Netherlands Organisation for Scientific Research (NWO). This research programme is cofinanced by Shell Global Solutions International B.V.

\section{References}

[1] Z. Chen, H.N. Dinh, E. Miller, Photoelectrochemical Water Splitting Standards, Experimental Methods, and Protocols, Springer, New York, 2013.

[2] N.S. Lewis, D.G. Nocera, Powering the planet: Chemical challenges in solar energy utilization, PNAS, 103 (43) (2006) 15729-15735.

[3] R. Van de Krol, M. Gratzel, editors. Photoelectrochemical hydrogen production, Springer, New York, 2012.

[4] C. McGlade and P. Ekins, The geographical distribution of fossil fuels unused when limiting global warming to $2^{\circ} \mathrm{C}$, Nature,517 (2015) 187-190.

[5] P.D. Tran, L.H. Wong, J. Barber, J.S.C. Loo, Recent advances in hybrid photocatalysts for solar fuel production, Energy Environ. Sci.,5 (2012) 7081-7089.

[6] H. J. Lewerenz, L. Peter, Photoelectrochemical water splitting: materials, processes and architectures, The Royal Society of Chemistry, RSC Energy and Environment Series, 2014.

[7] R. Isolda, M. A. Shipman and M. D. Symes, Earth-abundant catalysts for electrochemical and photoelectrochemical water splitting, Nat. Rev. Chem., 1 (2017) 0003, 1-13.

[8] K. Sivula, R. van de Krol, Semiconducting materials for photoelectrochemical energy conversion, Nat. Rev. Mater., 1 (2) (2016) 15010 (1-17).

[9] T. Bosserez, J. Ronge, J. van Humbeeck, S. Haussener, J. Martens, Design of compact photoelectrochemical cells for water splitting, Oil Gas Sci Technol.,70 (5) (2015) 877-889.

[10] A. Fujishima and K. Honda, Electrochemical photolysis of water at a semiconductor electrode, Nature, 238 (1972) 37-38. 
[11] M. Carmo, D.L. Fritz, J. Mergel, D. Stolten, A comprehensive review on PEM water electrolysis, Int J Hydrogen Energy, 38 (12) (2013)4901-4934.

[12] K.O. Iwu, A. Galeckas, A.Y. Kuznetsov, T. Norby, Solid-state photoelectrochemical $\mathrm{H}_{2}$ generation with gaseous reactants, Electrochim. Acta, 97 (2013) 320-325.

[13] S. Ichikawa, R. Doi, Hydrogen production from water and conversion of carbon dioxide to useful chemicals by room temperature photoelectrocatalysis, Catal. Today, 27 (1996) 271-277.

[14] B. Seger, P.V. Kamat, Fuel Cell Geared in Reverse: Photocatalytic Hydrogen production using a $\mathrm{TiO}_{2}$ /Nafion/Pt membrane assembly with no applied bias, J. Phys. Chem. C., 113 (2009) 1894618952.

[15] Y. Li, H. Yu, C. Yu, C. Zhang, W. Song, G. Li, Z. Shao, B. Yi, Effect of water and annealing temperature of anodized $\mathrm{TiO}_{2}$ nanotubes on hydrogen production in photoelectrochemical cell, Electrochim. Acta, 107 (2013) 313-319.

[16] R. Marschall, C. Klaysom, A. Mukherji, M. Wark, G.Q. Lu, L. Wang, Composite proton-conducting polymer membranes for clean hydrogen production with solar light in a simple photoelectrochemical compartment cell, Int. J. Hydrogen Energy, 37 (2012) 4012-4017.

[17] C. Ampelli, G. Centi, R. Passalacqu, S. Perathoner, Synthesis of solar fuels by a novel photoelectrocatalytic approach, Energy Environ. Sci., 3 (2010)292-301.

[18] J. Georgieva, S. Armyanov, I. Poulios, S. Sotiropoulos, An all solid photoelectrochemical cell for the photooxidation of organic vapours under ultraviolet and visible light illumination, Electrochem. Commun., 11 (2009) 1643-1646.

[19] J. Ronge, D. Nijs, S. Kerkhofs, K. Masschaele, J.A. Martens, Chronoamperometric study of membrane electrode assembly operation in continuous flow photoelectrochemical water splitting, Phys. Chem. Chem. Phys., 15 (2013) 9315-9325.

[20] J. Ronge, S. Deng, S. PulinthanathuSree, T. Bosserez, S.W. Verbruggen, N, Kumar Singh, J. Dendooven, M.B.J. Roeffaers F. Taulelle, M.DeVolder, C. Detavernier, J.A. Martens, Air-based photoelectrochemical cell capturing water molecules from ambient air for hydrogen production, RSC Adv., 4 (2014)29286-29290.

[21] J. Georgieva, S. Armyanov, I. Poulios, A.D. Jannakoudakis, S. Sotiropoulos, Gas phase photoelectrochemistry in a polymer electrolyte cell with a titanium dioxide/carbon/Nafionphotoanode. Electrochem. Solid-State Lett., , 13 (10) (2010)11-13.

[22] K.O. Iwu, A. Galeckas, S. Diplas, F. Seland, A.Y. Kuznetsov, T. Norby, Effects of temperature, triazole and hot-pressing on the performance of $\mathrm{TiO}_{2}$ photoanode in a solid-state photoelectrochemical cell, Electrochim. Acta, 115 (2014)66-74.

[23] A. Chatzitakis, M. Grandcolas, K. Xu, S. Mei, J. Yang, I.J.T. Jensen, C. Simon, Assessing the photoelectrochemical properties of $\mathrm{C}, \mathrm{N}, \mathrm{F}$ codoped $\mathrm{TiO}_{2}$ nanotubes of different lengths, Catal. Today, 287 (2017) 161-168.

[24] K. Xu, A. Chatzitakis, T. Norby, Solid-state photoelectrochemical cell with $\mathrm{TiO}_{2}$ nanotubes for water splitting, Photochem. Photobiol. Sci., 16 (2017)10-16.

[25] P. Lianos, Review of recent trends in photoelectrocatalytic conversion of solar energy to electricity and hydrogen, Appl. Catal. B, 210 (2017)235-254. 
[26] T. Stoll, G. Zafeiropoulos, M. N. Tsampas, solar fuel production in a novel polymeric electrolyte membrane photoelectrochemical (PEM-PEC) cell with a web of titania nanotube arrays as photoanode and gaseous reactants, Int. J. Hydrogen Energy, 41 (40) (2016)17807-17817.

[27] P. Roy, S. Berger, P. Schmuki, $\mathrm{TiO}_{2}$ Nanotubes: Synthesis and Applications, Angew. Chem. Int. Ed., 50 (2011) 2904-2939.

[28] D. Regonini, C.R. Bowen, A. Jaroenworaluck, R. Stevens, A review of growth mechanism, structure and crystallinity of anodized $\mathrm{TiO}_{2}$ nanotubes, Mater. Sci. Eng. R-Rep., 74 (2013)377406.

[29] Y. X. Chen, A. Lavacchi, H.A. Miller, M. Bevilacqua, J. Filippi, M. Innocenti, A. Marchionni, W. Oberhauser, L. Wang, F. Vizza, Nanotechnology makes biomass electrolysis more energy efficient than water electrolysis, Nat. Commun., 5 (2014)1-6.

[30] K. Gulati, A. Santos, D. Findlay, D. Losic, Optimizing Anodization Conditions for the Growth of Titania Nanotubes on Curved Surfaces, J. Phys. Chem. C, 119 (2015)16033-16045.

[31] A.S. Arico, M. Girolamo, S. Siracusano, D. Sebastian, V. Beglio, M. Schuster, Polymer electrolyte membranes for water photo-electrolysis, Membranes, 7 (2017)25 (1-16).

[32] D. Goossens, K. Synhaeve, J. De Baerdemaeker, The advantages of the use of porous metal fiber media in different alloys as gas diffusion layer in various energy storage systems, ECS Meeting Abstracts, 1 (2016)396.

[33] F. Amano, A. Shintani, K. Tsurui, Y.M. Hwang, Fabrication of tungsten trioxide photoanode with titanium microfibers as a three dimensional conductive back contact, Materials Letters, 199 (2017) 68-71.

[34] R. Espiritu, G. Golding, K. Scott, M. Mamlouk, Degradation of radiation grafted hydroxide anion exchange membrane immersed in neutral $\mathrm{pH}$ : removal of vinylbenzyltrimethylammonium hydroxide due to oxidation, J. Mater. Chem. A, 5 (2017)1248-1267.

[35] R. Espiritu, M. Mamlouk, K. Scott, Study on the effect of the degree of grafting on the performance of polyethylene-based anion exchange membrane for fuel cell application, Int.J. Hydrogen Energy, 41 (2016)1120-1133.

[36] S. Berger, J. Kunze, P. Schmuki, D. LeClere, A. T. Valota, P. Skeldon, G. E. Thompson, A lithographic approach to determine volume expansion factors during anodization: Using the example of initiation and growth of $\mathrm{TiO}_{2}$-nanotubes, Electrochim. Acta, 54 (2009)5942-5948.

[37] M. Kapilashrami, Y. Zhang, Y. Liu, A. Hagfeldt, J. Guo, Probing the optical property and electronic structure of $\mathrm{TiO}_{2}$ nanomaterials for renewable energy applications, Chem. Rev., 114 (19) (2014) 9662-9707.

[38] A. Beltrama, I. Romero-Ocana, J. J. Delgado Jaen, T. Montinia, P. Fornasiero, Photocatalytic valorization of ethanol and glycerol over $\mathrm{TiO}_{2}$ polymorphs for sustainable hydrogen production, Appl. Catal. A, 518 (2015)167-175.

[39] F. D. Hardcastle, H. Ishihara, R. Sharma, A. S. Biris, Photoelectroactivity and Raman spectroscopy of anodized titania $\left(\mathrm{TiO}_{2}\right)$ photoactive water-splitting catalysts as a function of oxygen-annealing temperature, J. Mater. Chem., 21 (17)(2011)6337-6345. 
[40] H. Lu, J. Zhao, L. Li, L. Gong, J. Zheng, L. Zhang, Z. Wang, J. Zhang, Z. Zhu, Selective Oxidation of Sacrificial Ethanol over $\mathrm{TiO}_{2}$-based Photocatalysts during Water Splitting, Energy Environ. Sci., 4 (2011)3384-3388.

[41] S. Ali and S. P. Hannula, Titania nanotube powders obtained by rapid breakdown anodization in perchloric acid electrolytes, J. Solid State Chem., 249 (2017)189-198.

[42] M. Jarosz, K. Syrek, J. Kapusta-Kolodziej, J. Mech, K. Malek, K. Hnida, T. Lojewski, M. Jaskula, G.D. Sulka, J. Phys. Chem., 119(2015)24182-24191.

[43] V. Swammy, Size-dependent modifications of the first-order Raman spectra of nanostructured rutile $\mathrm{TiO}_{2}$, Phys. Rev. B, 77 (2008)195414, 1-4.

[44] T. Mazza, E. Barborini, P. Piseri, P. Milani, D. Cattaneo, A. Li Bassi, C.E. Bottani, C. Ducati, Raman spectroscopy characterization of $\mathrm{TiO}_{2}$ rutile nanocrystals, Phys. Rev. B., 75 (2017)045416, 1-5.

[45] I. Dogan and M. C. M. van de Sanden, Direct characterization of nanocrystal size distribution using Raman spectroscopy, J. Appl. Phys., 114 (2013)134310, 1-8.

[46] C. Xu, Y. Song, L. Lu, C. Cheng, D. Liu, X. Fang, X. Chen, X. Zhu and D. Li, Electrochemically hydrogenated $\mathrm{TiO}_{2}$ nanotubes with improved photoelectrochemical water splitting performance, Nanoscale Res. Lett.,8 (2013) 391, 1-7.

[47] Y. Sun, K. Yan, G. Wang, W Guo, T. Ma, Effect of Annealing Temperature on the Hydrogen Production of $\mathrm{TiO}_{2}$ Nanotube Arrays in a Two-Compartment Photoelectrochemical Cell, J. Phys. Chem. C, 115 (26) (2011) 12844-12849.

[48] R. Sharma, P. P. Das, M. Misra, V. Mahajan, J. P. Bock, S. Trigwell, A. S. Biris, M. K. Mazumder, Enhancement of the photoelectrochemical conversion efficiency of nanotubular $\mathrm{TiO}_{2}$ photoanodes using nitrogen plasma assisted surface modification, Nanotechnology, 20 (7) (2009) 075704, 1-7.

[49] N. K. Allam, and M. A. El-Sayed, Photoelectrochemical Water Oxidation Characteristics of Anodically Fabricated $\mathrm{TiO}_{2}$ Nanotube Arrays: Structural and Optical Properties, J. Phys. Chem. C, 114 (27) (2010)12024-12029.

[50] H. Ali, N. Ismail, M.S. Amin, M. Mekewi, Efficient photoelectrodes from anatase TiO2 nanotube arrays decorated with particles/rods/3D microflower rutile crystals for photoelectrochemical water splitting, J. Solid State Electrochem., in press, 21 (6)(2017)1605-1613.

[51] Y. Mi and Y. Weng, Band alignment and controllable electron migration between rutile and anatase $\mathrm{TiO}_{2}$, Sci. Rep., 5 (2015)11482, 1-10.

[52] T. Luttrell, S. Halpegamage1 J. Tao, A. Kramer, E. Sutter, M. Batzill, Why is anatase a better photocatalyst than rutile? - Model studies on epitaxial $\mathrm{TiO}_{2}$ films, Sci. Rep., 4 (2014)4043, 1-8.

[53] B. Moss, K.K. Lim, A. Beltram, S. Moniz, J. Tang, P. Fornasiero, P. Barnes, J. Durrant, A. Kafizas, Comparing photoelectrochemical water oxidation, recombination kinetics and charge trapping in the three polymorphs of $\mathrm{TiO}_{2}$, Sci. Rep., 7 (2017) 2938, 1-7.

[54] A. Haryanto, S. Fernando, N. Murali, S. Adhikari, Current Status of Hydrogen Production Techniques by Steam Reforming of Ethanol: A Review, Energy Fuels, 19 (5) (2005) 2098-2106.

[55] M. Ni, D. Y. C. Leung, M. K. H. Leung, A review on reforming bio-ethanol for hydrogen production, Int. J. Hydrogen Energy, 32 (15) (2007)3238-3247. 
[56] Y. K. Kho, A. Iwase, W. Y. Teoh, L. Mädler, A. Kudo, R. Amal, Photocatalytic $\mathrm{H}_{2}$ Evolution over $\mathrm{TiO}_{2}$ Nanoparticles. The Synergistic Effect of Anatase and Rutile, J. Phys. Chem. C, 114 (6) (2010)28212829.

[57] A. Veres, J. Ménesi, C. Janáky, G. F. Samu, M. K. Scheyer, Q. Xu, F. Salahioglu, M. V. Garland, I. Dékán, Z. Zhong, New insights into the relationship between structure and photocatalytic properties of TiO2 catalysts, RSC Adv., 5 (2015)2421-2428.

[58] V. Collins-Martínez, A. L. Ortiz, and A. A. Elguézabal, Influence of the anatase/rutile ratio on the $\mathrm{TiO}_{2}$ photocatalytic activity for the photodegradation of light hydrocarbons, Int. J. Chem. React. Eng., 5 (2007)A92, 1-11.

[59] A. Sclafani, L. Palmisano, M. Schiavello, Influence of the preparation methods of $\mathrm{TiO}_{2}$ on the photocatalytic degradation of phenol in aqueous dispersion, J. Phys. Chem., 94 (1990)829-832.

[60] A.K. Seferlis, S. Neophytides, Photoelectrocatalytic Electricity and/or $\mathrm{H}_{2}$ production from alcohols: the effect of $\mathrm{TiO}_{2}$ film thickness, J. Electrochem. Soc., 158 (2) (2011)183-189.

Supplementary information for 


\title{
Porous titania photoelectrodes built on a Ti-web of microfibers for polymeric electrolyte membrane photoelectrochemical (PEM-PEC) cell applications
}

\author{
G. Zafeiropoulos ${ }^{a}$, T. Stoll ${ }^{a}$, I. Dogan ${ }^{a}$, M. Mamlouk ${ }^{b}$, M.C.M. van de Sanden ${ }^{a}$, M.N. Tsampas ${ }^{a, *}$

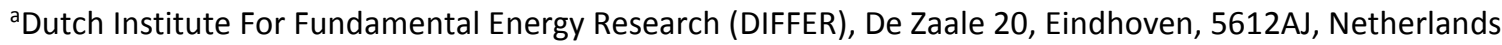 \\ bUniversity of Newcastle, School of Chemical Engineering and Advanced Materials, Merz Court Newcastle upon \\ Tyne NE1 7RU, UK \\ *Corresponding author: $\underline{\text { m.tsampas@differ.nl }}$
}

Contents:

Fig. S1 Chopped light linear voltammetry sweeps $\left(2.5 \mathrm{mV} \mathrm{s}^{-1}\right)$ on the TNTAs (a) and $\mathrm{TiO}_{2}$ layers (b) photoanodes annealed at $600^{\circ} \mathrm{C}$ under UV illumination (grey line) and illumination by solar simulator AM 1.5G (black line) in aqueous electrolyte $\left(0.1 \mathrm{M} \mathrm{H}_{2} \mathrm{SO}_{4}\right)$

Fig. S2 Nitrogen adsorption - desorption isotherm (a) and pore size distribution curve (b) of the anodized sample annealed at $450^{\circ} \mathrm{C}$.

Fig. S3 Stability measurements for TNTAs (a) and $\mathrm{TiO}_{2}$ overlayers (b) photoanodes annealed at $600^{\circ} \mathrm{C}$ under chopped UV light illumination at $1.2 \mathrm{~V}$ vs RHE.

Table S1 XRD parameters of anodized samples annealed at different temperatures.

Table S2 Photoelectrochemical activity of class-A and class-B photoanodes at different annealing temperatures at $1.23 \mathrm{~V}$ vs RHE .

Table S3 Photocurrent enhancement (or reduction) after ethanol addition at 1.23V vs RHE for both photoanode classes.

Table S4 Photocurrent enhancement (or reduction) after the addition of (poly)alcohols for both classes of photoanodes annealed at $450^{\circ} \mathrm{C}$ at $1.23 \mathrm{~V}$ vs RHE.

Table S5 Photon to hydrogen efficiency at 0.6V vs RHE in the conventional and in the PEM-PEC cell for class-A and class-B photoanode annealed at $600^{\circ} \mathrm{C}$. 
Photoanodes class-A: Ti-web with TNTAs

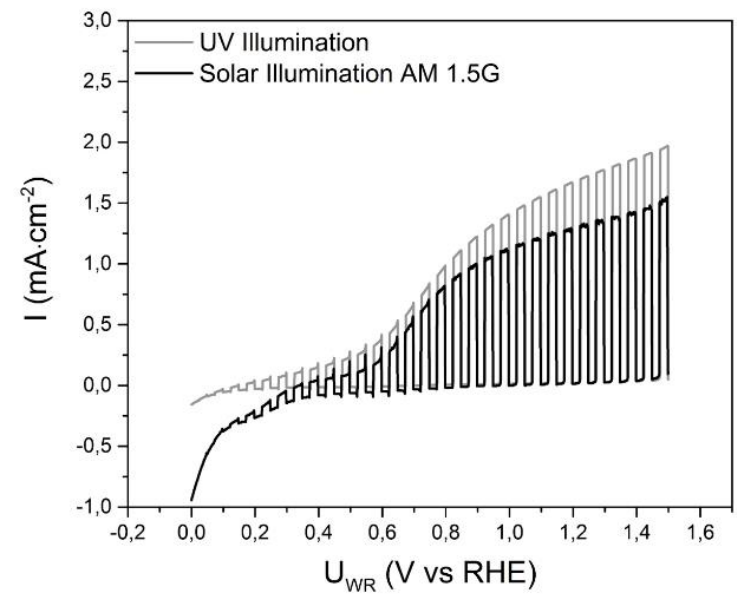

(a)

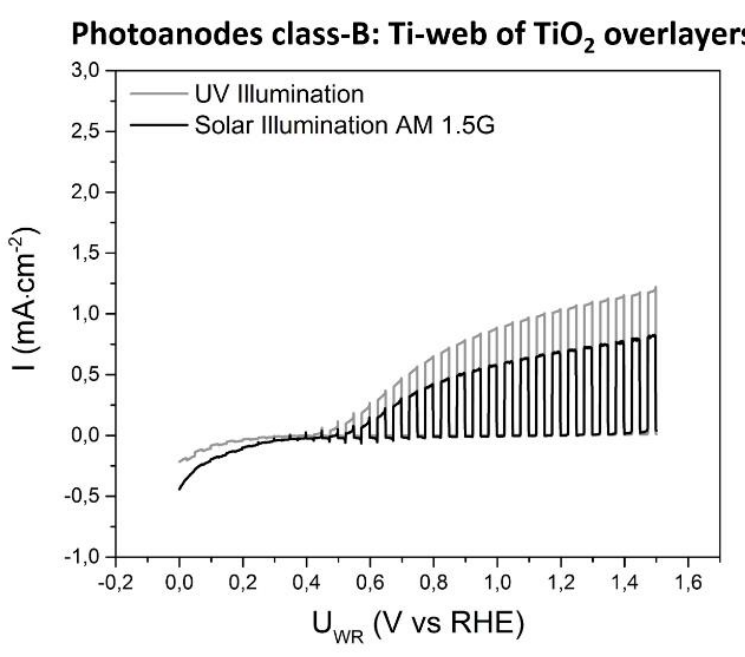

(b)

Fig. S1 Chopped light linear voltammetry sweeps $\left(2.5 \mathrm{mV} \mathrm{s}^{-1}\right)$ on the TNTAs (a) and $\mathrm{TiO}_{2}$ layers (b) photoanodes annealed at $600^{\circ} \mathrm{C}$ under UV illumination (grey line) and illumination by solar simulator AM 1.5G (black line) in aqueous electrolyte $\left(0.1 \mathrm{M} \mathrm{H}_{2} \mathrm{SO}_{4}\right)$

The photoelectrodes were illuminated by a 150 W Xe lamp (66477-150XF-R1, Newport) with an AM 1.5 Global filter and an IR removal water filter. The light intensity was tuned with a reference cell and meter from Newport (91150V) to $100 \mathrm{~mW} \mathrm{~cm}^{-1}$ in order to reach one sun illumination on the photoelectrode surface. Fig. S1 shows the performance of the photoelectrodes of both classes that were $\mathrm{O}_{2}$ annealed at $600^{\circ} \mathrm{C}$ under UV-LED lamp and AM $1.5 \mathrm{G}$ illumination during chopped light illumination. In both cases the obtained photocurrent under UV illumination is higher than the one obtained under visible light irradiation. Moreover at $1.23 \mathrm{~V}$ vs RHE the photocurrent under UV illumination is $23 \%$ higher than in the case of AM $1.5 \mathrm{G}$ illumination for the class-A photoelectrode, while the difference for the class-B photoelectrode is $33 \%$.

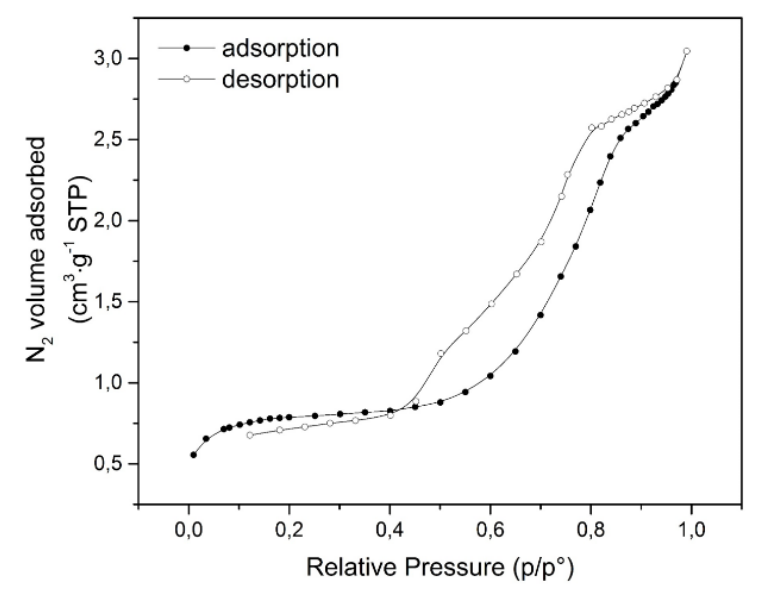

(a)

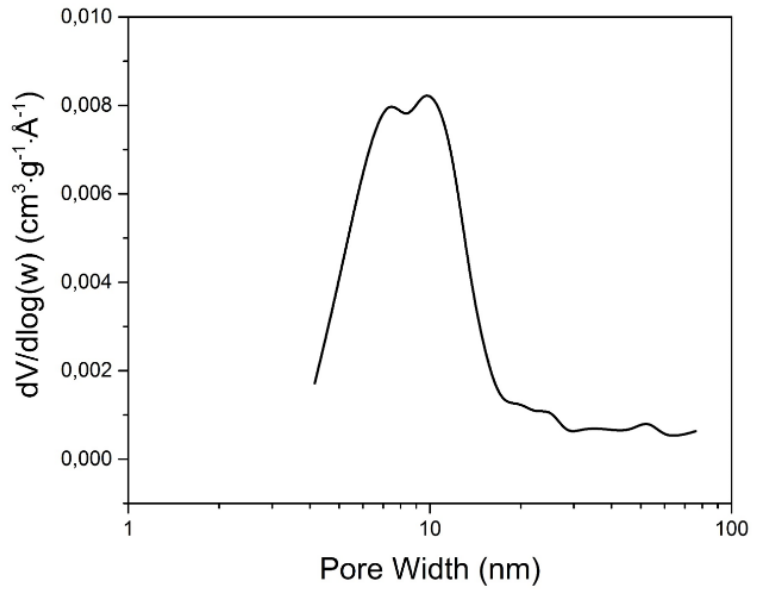

(b)

Fig. S2 Nitrogen adsorption - desorption isotherm (a) and pore size distribution curve (b) of the anodized sample annealed at $450^{\circ} \mathrm{C}$. 
Fig. S2a illustrates the $\mathrm{N}_{2}$ adsorption-desorption isotherm derived from the class-A photoanode which was annealed at $450^{\circ} \mathrm{C}$. According to the IUPAC classification, the sample is categorised as type IV which is reported for mesoporous materials $(2-50 \mathrm{~nm})$. The hysteresis loop type of the nanotubes in this case resembles H1-type which corresponds to cylindrical shaped channels [1].

Figure S2b demonstrates the pore size distribution (PVD) curve of the same sample. The sample presents a narrow dual-peak pore size distribution between 4 and $11 \mathrm{~nm}$, maximized at 7.4 and $9.7 \mathrm{~nm}$, respectively. These values are in good agreement with the nanotube diameter estimated by the SEM images. At the same time the specific pore volume is considerably low at $4.4 \cdot 10^{-3} \mathrm{~cm}^{-3} \cdot \mathrm{g}^{-1}$.

The anodization process grows TNTAs on top of the nanofibers, thus the measured sample was not consisted fully of nanotubes, but also of material derived from the substrate. This factor could not be taken into account while weighting the sample during the $\mathrm{N}_{2}$ adsorption-desorption measurement and contributed to low SSA $\left(2.7 \mathrm{~m}^{2} \cdot \mathrm{g}^{-1}\right)$ and pore volume.

Such SSA measurements for TNTAs developed on top of a substrate are not commonly mentioned in the literature but they could serve as example of an indicative order of magnitude of the nanotube surface area. The experimental setups for conducting such kind of measurements are designed for powder samples with very high surface area. Thus in order to successfully measure the surface area we fabricated $10 \mathrm{~cm}^{2}$ photoelectrodes which were cut in $3 \times 3 \mathrm{~mm}$ pieces in order to be compatible in the Tristar 3000 automated gas adsorption system. We tried to compare our results with literature studies [2] however we could not find similar measurements most likely due to the complexity of the process.

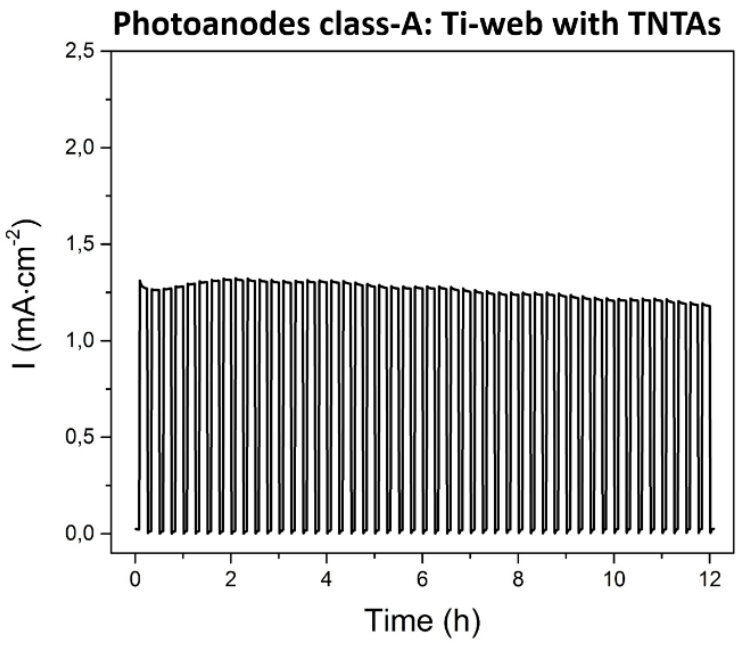

(a)

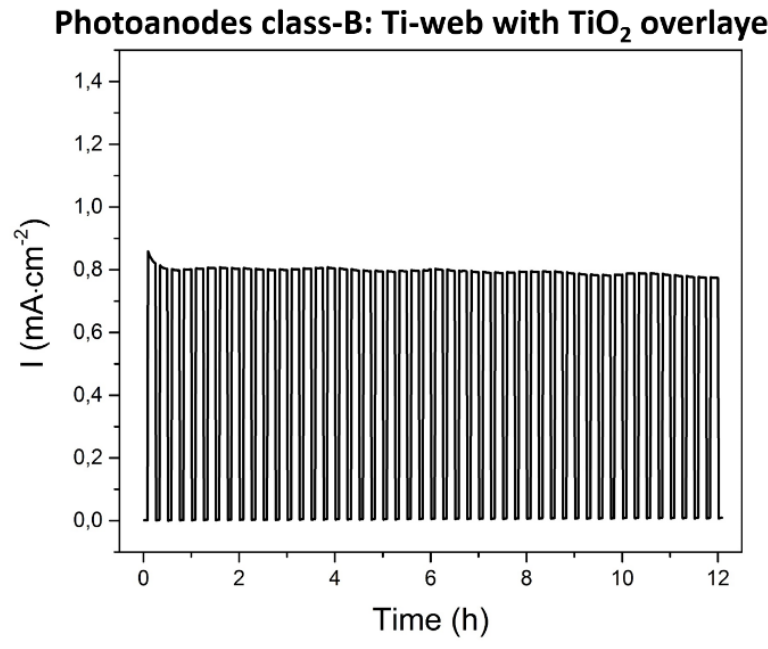

(b)

Fig. S3 Stability measurements for TNTAs (a) and $\mathrm{TiO}_{2}$ overlayers (b) photoanodes annealed at $600^{\circ} \mathrm{C}$ under chopped UV light illumination at $1.2 \mathrm{~V}$ vs RHE.

In order to investigate the stability and performance the PEM-PEC cell (under various cycles of operation), two long term experiments were performed. The duration of the experiments were $12 \mathrm{~h}$ under chopped light illumination using the photoanodes from both classes that were annealed at the same temperature (i.e. $600^{\circ} \mathrm{C}$ ). Every experiment consists of successive illumination of each photoanode for 10 minutes, followed by a 5 -minute dark current measurement for 50 cycles in total. Class-A photoanode exhibits small fluctuation on the obtained photocurrent but it is considered stable as its performance at the end of the experiment drops by $8 \%$ while class-B photoanode demonstrates extremely high stability as the photocurrent during the last cycle is reduced only by $4 \%$ versus the second experimental cycle. 
Table S1 XRD parameters of anodized samples annealed at different temperatures.

\begin{tabular}{|c|c|c|c|c|c|}
\hline $\begin{array}{c}\text { Calcination } \\
\text { temperature } \\
\left({ }^{\circ} \mathrm{C}\right)\end{array}$ & Phase & $\begin{array}{l}\text { FWHM } \\
\text { (degree) }\end{array}$ & $\begin{array}{l}\text { Intensity } \\
\text { (counts) }\end{array}$ & $\begin{array}{l}\text { Rutile/anatase } \\
\text { intensity ratio }\end{array}$ & $\begin{array}{l}\text { Crystallite } \\
\text { size }(\mathrm{nm})\end{array}$ \\
\hline 400 & $\begin{array}{c}\text { Anatase } \\
\text { Rutile }\end{array}$ & $\begin{array}{c}0.347 \\
-\end{array}$ & $\begin{array}{c}6924 \\
-\end{array}$ & 0 & $\begin{array}{c}23.4 \\
-\end{array}$ \\
\hline 450 & $\begin{array}{c}\text { Anatase } \\
\text { Rutile }\end{array}$ & $\begin{array}{c}0.320 \\
-\end{array}$ & $\begin{array}{c}7372 \\
-\end{array}$ & 0 & $\begin{array}{c}25.4 \\
-\end{array}$ \\
\hline 500 & $\begin{array}{l}\text { Anatase } \\
\text { Rutile }\end{array}$ & $\begin{array}{l}0.400 \\
0.393\end{array}$ & $\begin{array}{l}5791 \\
449\end{array}$ & 0.078 & $\begin{array}{l}20.3 \\
20.8\end{array}$ \\
\hline 550 & $\begin{array}{c}\text { Anatase } \\
\text { Rutile }\end{array}$ & $\begin{array}{l}0.275 \\
0.303\end{array}$ & $\begin{array}{l}9101 \\
1903\end{array}$ & 0.209 & $\begin{array}{l}29.5 \\
27.0\end{array}$ \\
\hline 600 & $\begin{array}{c}\text { Anatase } \\
\text { Rutile }\end{array}$ & $\begin{array}{l}0.238 \\
0.209 \\
\end{array}$ & $\begin{array}{l}9429 \\
8059 \\
\end{array}$ & 0.855 & $\begin{array}{l}34.1 \\
39.1 \\
\end{array}$ \\
\hline
\end{tabular}

The most characteristic anatase and rutile peaks are the ones at $25.2^{\circ}$ and $27.3^{\circ}$ respectively. The crystal grain size was calculated using Sheerer's equation and K constant was equal to 0.9 which corresponds to polycrystaline materials $[3,4]$. As the temperature increases, the peak intensity is also increased, while the full width at half maximun FWHM and the crystal grain size are reduced. The observed tendency for the crystal grain size is in agreement with the results obtained from Raman spectrometry.

Table S2 Photoelectrochemical activity of class-A and class-B photoanodes at different annealing temperatures at $1.23 \mathrm{~V}$ vs RHE .

\section{Photocurrent $\left(\mathrm{mA} \cdot \mathrm{cm}^{-2}\right)$ at $1.23 \mathrm{~V}$ vs RHE}

Calcination

temperature $\left({ }^{\circ} \mathrm{C}\right)$

Class-A, anodized

Class-B, untreated

\begin{tabular}{lll}
\hline $\mathbf{4 0 0}$ & 0.52 & 0.26 \\
\hline $\mathbf{4 5 0}$ & 0.60 & 0.29 \\
\hline $\mathbf{5 0 0}$ & 0.73 & 0.34 \\
\hline $\mathbf{5 5 0}$ & 1.20 & 0.71 \\
\hline $\mathbf{6 0 0}$ & 1.71 & 1.04 \\
\hline
\end{tabular}

The photoelectrodes of class-A and class-B were tested for ethanol photooxidation. The results are summarized in Table S3 where the reduction of the photocurrent enhancement is evident for class-A electrodes as the rutile/anatase ratio is increased. On the contrary class-B photoelectrodes are consisted only by rutile and thus instead of an increase, a minor decrease of the measured photocurrent is observed. 
Table S3 Photocurrent enhancement (or reduction) after ethanol addition at $1.23 \mathrm{~V}$ vs RHE for both photoanode classes.

\begin{tabular}{cccc}
\hline & \multicolumn{2}{c}{$\begin{array}{c}\text { Photocurrent enhancement or reduction } \\
\text { upon the EtOH addition at 1.23V vs RHE (\%) }\end{array}$} \\
\hline $\begin{array}{c}\text { Calcination } \\
\text { temperature }\left({ }^{\circ} \mathrm{C}\right)\end{array}$ & $\begin{array}{c}\text { Class-A, anodized } \\
\text { Rutile / anatase } \\
\text { intensity ratio }\end{array}$ & Class-B, untreated (rutile) \\
\hline & \multicolumn{3}{c}{-3} \\
\hline $\mathbf{4 5 0}$ & 41 & 0 & -3 \\
\hline $\mathbf{5 0 0}$ & 27 & 0.078 & -3 \\
\hline $\mathbf{5 5 0}$ & 18 & 0.209 & -4 \\
\hline $\mathbf{6 0 0}$ & 9 & 0.855 & \\
\hline
\end{tabular}

Taking into account the role of anatase in ethanol photooxidation we investigated the effect of different (poly)alcohol additives on the photocurrent, by testing the class-A photoanode which was $\mathrm{O}_{2}$ annealed at $450^{\circ} \mathrm{C}$ (Table S4). Our results indicate that the use of ethanol and methanol as sacrificial agents is more beneficial than the use of iso-propanol or glycerol, which is probably related with adsorption and electrokinetic effects. As far as class-B photoanodes are concerned, there is a slight reduction in the measured photocurrent for methanol and ethanol which is more eminent than isopropanol and glycerol.

Table S4 Photocurrent enhancement (or reduction) after the addition of (poly)alcohols for both classes of photoanodes annealed at $450^{\circ} \mathrm{C}$ at $1.23 \mathrm{~V}$ vs RHE.

\begin{tabular}{ccccc}
\hline & \multicolumn{3}{c}{$\begin{array}{c}\text { Photocurrent enhancement or reduction } \\
\text { upon the (poly)alcohol addition at 1.23V vs RHE (\%) }\end{array}$} \\
\hline \multicolumn{5}{c}{ Additive } \\
\hline Photoanode & $\mathrm{m}$ PrOH & Glycerol \\
\hline Class-A, anodized & 39 & EtOH & 34 & 31 \\
\hline Class-B, untreated & -7 & 40 & -14 & -15 \\
\hline
\end{tabular}

The photon to hydrogen efficiency is defined as the ratio between the power used in water splitting and the input light power using the following equation [5]:

$$
\eta=I_{p}\left(1.23-V_{\text {bias }}\right) / J_{\text {light }}
$$

$\mathrm{I}_{\mathrm{p}}$ : photocurrent density; $1.23 \mathrm{~V}$ : thermodynamic water splitting potential; $\mathrm{V}_{\text {bias}}$ : applied external potential; Jlight: light irradiance.

The photon to hydrogen efficiency was calculated at $0.6 \mathrm{~V}$ vs RHE using the values from Figure 11 . The results are summarized in Table $\mathrm{S} 5$, where the liquid phase operation in $\mathrm{pH}=1$ and the gas phase operation using a $\mathrm{H}^{+}$conductive membrane for the class-A photoelectrode have identical photon to hydrogen efficiency (i.e. 2.7\%). Respectively, the same photoelectrode demonstrates three and four times higher photon to hydrogen efficiency in liquid phase operation in $\mathrm{pH}=13$ using a $\mathrm{OH}$ - conducting membrane. These values are significantly higher than the ones that were reported (i.e. 1.13\%) when measured in alkaline environment, for nanotube arrays fabricated on a Ti-mesh [5]. Class-B photoanode demonstrates almost $40 \%$ lower photon to hydrogen efficiency at $0.6 \mathrm{~V}$ vs RHE regardless the $\mathrm{pH}$ value and the conducting membrane type. 
Table S5 Photon to hydrogen efficiency at $0.6 \mathrm{~V}$ vs RHE in the conventional and in the PEM-PEC cell for class-A and class-B photoanode annealed at $600^{\circ} \mathrm{C}$.

\begin{tabular}{ccccc}
\hline & \multicolumn{3}{c}{ Photon to hydrogen efficiency at 0.6 V vs RHE } \\
\hline Photoanode & \multicolumn{2}{c}{$\begin{array}{c}\text { Conventional PEC } \\
\text { (liquid operation) }\end{array}$} & \multicolumn{2}{c}{ PEM-PEC } \\
& (gas phase operation with He carrier) \\
\hline Calcined at $\mathbf{6 0 0 ^ { \circ } \mathrm { C }}$ & $\mathrm{pH}=1$ & $\mathrm{pH}=13$ & $\mathrm{H}^{+}$conducting & $\mathrm{OH}^{-}$conducting \\
\hline class-A, anodized & 2.7 & 7.5 & 2.7 & 9.1 \\
\hline class-B, untreated & 1.7 & 4.4 & 1.6 & 5.3 \\
\hline
\end{tabular}

\section{References}

[1] G. Leofanti, M. Padovan, G. Tozzola, B. Venturelli, Surface area and pore texture of catalysts, Catalysis Today, 41 (1998) 207-219.

[2] C.A. Grimes \& G.K. Mor, $\mathrm{TiO}_{2}$ Nanotube Arrays: Synthesis, Properties and Applications, Springer, Berlin, 2009.

[3] A. Monshi, M. R. Foroughi, M. R.monshi, Modified Scheerer equation to estimate more accurately nano-crystalite size using XRD, WJNSE, 2 (2012) 154-160.

[4] F. T. L. Muniz, M. A. R. Miranda, C. M. dos Santos, J. M. Sasaki, The Scherrer equation and the dynamical theory of X-ray diffraction, Acta Crystallogr. A Found. Adv., 72 (2016) 385-390.

[5] Y.Li, H. Yu, C. Zhang, W. Song, G. Li, Z. Shao, B. Yi, Effect of water and annealing temperature of anodized $\mathrm{TiO}_{2}$ nanotubes on hydrogen production in photoelectrochemical cell, Electrochim. Acta, 107 (2013) 313-319. 